\title{
Local heat transfer coefficients at the inlet of an annular flow passage
}

Jaco Dirker*, Josua P. Meyer***, Berno W Kohlmeyer

Department of Mechanical and Aeronautical Engineering, University of Pretoria, Pretoria, Private Bag X20, Hatfield 0028, South Africa

${ }^{*}$ Corresponding author:

Email address: jaco.dirker@up.ac.za

Phone: +27 (0)124202465

**Alternative corresponding author:

Email address: josua.meyer@up.ac.za

Phone +27(0)12 4203104 


\begin{abstract}
Annular flow geometries are commonly found in several heat exchange devices, however, relatively little experimental work has been done specifically to determine the local heat transfer coefficients in developing flow in annuli. In this experimental study circumferentially averaged local heat transfer coefficients were determined with water for a uniform heat flux boundary condition on the inner wall in a horizontal concentric annular test section with a length of $1.05 \mathrm{~m}$, a hydraulic diameter of $14.8 \mathrm{~mm}$, and a diameter ratio of 0.648 . Local inner wall temperatures were obtained via liquid crystal thermography with the aid of an automated camera position system. Conventional oncentre and off-centre annular inlet configurations with three inlet sizes were evaluated for Reynolds numbers ranging from 2000 to 7500 . It was found that the local heat transfer coefficients were significantly higher at the inlet, and decreased as the boundary layers developed. Local maximum and minimum heat transfer coefficients were identified which may be due to flow impingement caused by the inlet geometry. A new local heat transfer correlation for the turbulent flow in regions close to the inlet of an annular flow passage was developed.
\end{abstract}




\section{Keywords}

Local heat transfer coefficients; turbulent flow; liquid crystal thermography; annulus; developing flow 


\section{Introduction}

Efficient heat transfer in heat exchangers is an important energy transfer method in a wide spectrum of applications, including engineered power conversion systems, cooling systems and heating systems. Inefficiencies resulting from thermal resistance reduce the rate at which heat can be transferred and lead to exergy destruction. Convective heat transfer thermal resistance increases with the development of thermal and velocity boundary layers. If not disturbed, these boundary layers increase in thickness and might merge when the flow reaches a fully developed state. By using shorter heat transfer lengths or by purposefully imposing flow disruptions, higher averaged convection heat transfer coefficients can be sustained.

Due to the simplicity of their design, and their ability to withstand high pressures, concentric annular flow passages are found in many heat transfer applications including heat exchangers, nuclear industry cooling applications and fluid heating applications. The fluid flow state may be categorised as laminar, transitional or turbulent, where turbulent flow yields the highest heat transfer ability.

Because of its wide use, several researchers have investigated the heat transfer and pressure drop characteristics of annular flow passages [1-8]. Several heat transfer coefficient and friction factor correlations have been developed to predict the effective average heat transfer coefficient and friction factor along the length of the heat exchanger. Parameters that are commonly present in the correlations include the Reynolds Number, the Prandtl number, a geometric parameter such as the diameter ratio, and in some instances, the friction factor. It has, however, been reported that some of the correlations differ in estimating the magnitude of heat transfer rate [1] [3]. This could be due to less than accurate experimental data, difficulties in obtaining inner wall temperature values, different boundary conditions, and possibly different length-to-diameter ratios considered during experimental test runs. 
Because some parallels exist between flow in circular tubes and flow in annuli, correlation development for annular passages are often also based on experimental findings obtained from circular tubes, especially due to the abundance of relevant experimental data for circular tubes. Correlations for turbulent heat transfer in circular tubes have been published by authors such as Dittus and Boelter [9], Sieder and Tata [10], Prandtl [11], McAdams [12] and Gnielinski [13]. In most correlations, the increased heat transfer in the inlet region due to boundary layer development is not specifically taken into consideration in the mathematical formulations. Authors who accounted for the increased heat transfer in the inlet region by including a term considering the length of the heat transfer tube include Nusselt [14], Hausen [15], Bhatti and Shah [16], Badus'haq [17], Geankoplis [18], Ghajar and Tam [19] and Gasljevic and Matthys [20]. These correlations all refer to circular tubes.

A number of correlations attempt to describe the heat transfer ability for turbulent flow in concentric annular flow passages. These include the correlations of McAdams [12], Dirker and Meyer [1], Swamee et al. [21] and Gnielinski [3]. According to our knowledge, the only correlation that considers boundary layer development by including a length factor, is the correlation of Gnielinski [3]. developed for Reynolds numbers from $10 \quad 000$ upwards. Compared to circular tube correlations, there are significantly fewer annulus flow correlations and relatively little to no work is found that looks specifically at the entrance region, or for Reynolds numbers below 10000.

A major difficulty encountered when attempting to address this gap arises with the measurement of the heat transfer coefficient in the entrance region without influencing heat transfer and fluid flow characteristics. In order to determine local heat transfer coefficients, wall heat flux values, as well as wall and bulk fluid temperature measurements, are needed. Temperature measurements are often captured using thermocouples. However, thermocouples are notorious for influencing the heat transfer and altering fluid flow, especially since it is 
difficult to prevent fluid interaction with the thermocouple lead wires when internal local wall temperature are needed. Hence, less intrusive alternative techniques to measure the wall temperature need to be considered. Such methods can include thermistors, pyrometers, thermographic techniques, thermal cameras, and liquid crystal thermography.

A method that is adaptable to wetted surface investigations is liquid crystals thermography (LCT) which uses thermochromic liquid crystals (TLCs) that exhibit modified reflected colours in the visible spectrum, depending on the crystal temperature. When applied to a heat transfer surface it can be used to determine the wall temperature, or it can be dispersed within a fluid itself to obtain the local fluid temperature. In relative terms, such approaches interfere little with the fluid flow. In the study by Van der Westhuizen et al. [22] it was shown that this technique is suitable to capture the local surface temperature field on the inner wall of an annular flow passage. It offers great opportunity to gather the detailed temperature field in order to calculate the local heat transfer coefficients.

Therefore, based on the literature thus far mentioned, the heat transfer in the inlet region of a concentric annular flow passage has not been investigated adequately. Also, limited experimental data is available which specifically describe the thermally and hydrodynamically developing boundary layer regions. There is a specific gap in knowledge in the turbulent Reynolds number range below 10000 and little is known about the upper limit of the transitional flow regime based on local heat transfer coefficients. Furthermore, the influence of the inlet type on the local heat transfer coefficients are not well understood.

The purpose of this study was thus to conduct experimental work in order to determine the local heat transfer coefficients for a short concentric annular flow passage. Different in-line and out-of-line inlet geometries were considered in the turbulent flow regime with relatively low Reynolds numbers. The upper limit of the transitional flow regime was also briefly 
considered. The ultimate aim was to develop a heat transfer correlation that considers boundary layer development for the low turbulent flow regime which might assist thermal design engineers to better predict the heat transfer coefficients for short annular flow passages.

\section{Experimental apparatus and procedure}

In this section the experimental test facility, the test section, the imaging mechanism needed for the thermography technique, and the experimental procedure are discussed.

\subsection{Experimental test facility}

The experimental facility is shown in Figure 1. It consisted of a cold-water loop (shown in blue) and an annular flow passage test section that was electrically heated. The cold-water flow loop was connected to a 1000 -litre reservoir, in which water was thermostatically kept at $20^{\circ} \mathrm{C}$ $\left( \pm 1{ }^{\circ} \mathrm{C}\right)$ by means of a cooling system that was serviced by a $16.5 \mathrm{~kW}$ chiller. A positive displacement pump (with a maximum volume flow rate of $2000 \mathrm{l} / \mathrm{h}$ ) was used to circulate the water from the reservoir to the test section and back. The pump was controlled by a frequency drive to achieve specific mass flow rates. A four-litre blade accumulator was installed downstream from the positive displacement pump to dampen flow. The mass flow rate through the test section was measured with a Coriolis mass flow rate meter with a range of $0.0151 \mathrm{~kg} / \mathrm{s}$ to $0.606 \mathrm{~kg} / \mathrm{s}$ and a measurement uncertainty of $0.11 \%$ of the reading. Hand-operated ball valves were installed in the flow loop to allow or restrict flow to certain sections of the flow loop.

The test section (discussed shortly) was electrically heated by a heating element that was powered by an Elektro-Automatik (EA 8360-30) direct current (DC) power supply with power, voltage, and current ratings of $3 \mathrm{~kW}, 360 \mathrm{~V}$ and $8.33 \mathrm{~A}$ respectively. Actual power, voltage and current values were digitally displayed on the power supply with an uncertainty of $0.2 \%$ of the respective readings. 


\subsection{Test section}

A short concentric annular flow passage was considered in this study as is shown schematically in Figure 2. The inner wall consisted of an inner heated rod that was specifically prepared to produce a uniform heat flux, while the outer wall consisted of a transparent acrylic glass tube. The test section had a wetted surface length of $L_{w s}=1050$ $\mathrm{mm}$, an inner wall diameter of $D_{1}=27.2 \mathrm{~mm}( \pm 10 \mu \mathrm{m})$ and an outer wall diameter of $D_{2}=42$ $\mathrm{mm}( \pm 10 \mu \mathrm{m})$. This resulted in an annular diameter ratio of $a=D_{1} / D_{2}=0.648$ and a hydraulic diameter of $D_{h}=D_{2}-D_{1}=14.8 \mathrm{~mm}$.

The inlet passage (also shown in isometric view in Figure 3) had an inner diameter of $D_{3}$, was perpendicular to the main annular flow passage, and was placed $810 \mathrm{~mm}$ upstream from the outlet. The outlet had the same diameter as the inlet and was placed in the same plane as the inlet. This is similar to commercial inlet and outlet configurations. The inner diameter and the axial alignment of the inlet and outlet ports could be changed by inserting carefully machined nylon bushes into the inlet and outlet tubes. On-centre inlets where obtained by placing the centre of the inlet passage on the centre line of the annulus, while an off-centre inlet could be obtained by purposefully placing the inlet port off-centre from the centre line of the annulus. Three on-centre inlet configurations were investigated. These were: Case A which had inlet and outlet diameters of $D_{3}=20 \mathrm{~mm}( \pm 10 \mu \mathrm{m})$, Case B which had inlet and outlet diameters of $D_{3}=15 \mathrm{~mm}$, and Case C which had inlet and outlet diameters of $D_{3}=10$ $\mathrm{mm}$. One off-centre inlet configuration, Case D, was considered with inlet and outlet diameters of $D_{3}=10 \mathrm{~mm}$, but with the inlet placed $3.5 \mathrm{~mm}$ off-centre so that it would produce a swirl flow pattern around the inner tube along the axial length of the heat exchanger. The outlet of the annulus was kept on-centre for all cases. 
As mentioned, the outer wall of the annulus was constructed from an acrylic glass tube. The outer tube had a wall thickness of $4 \mathrm{~mm}$ and a thermal conductivity of $0.19 \mathrm{~W} / \mathrm{mK}$ [23], while the inner wall was formed by the presence of the inner heated rod. The inner rod had several internal layers, and was manufactured by winding electrically insulated constantan heating wire around a solid bright steel rod and placing this inside a seamless stainless steel 304 tube and filling the small annular space between the wound wire and stainless steel with aluminium powder. Refer to Figure 3 for a graphical representation of the internal structure of the inner rod. The constantan wire had a diameter of $0.25 \mathrm{~mm}$; the solid bright steel rod had a diameter of $12 \mathrm{~mm}$ and a thermal conductivity of $51.9 \mathrm{~W} / \mathrm{mK}$ [24]; the stainless steel rod had an inner diameter of $20.93 \mathrm{~mm}( \pm 10 \mu \mathrm{m})$, an outer diameter of $26.67 \mathrm{~mm}( \pm 10 \mu \mathrm{m})$, a length of $1 \mathrm{~m}( \pm 1 \mathrm{~mm})$, and a thermal conductivity of $14.9 \mathrm{~W} / \mathrm{mK}[23]$; and the aluminium powder had a calculated effective thermal conductivity, of $61.4 \mathrm{~W} / \mathrm{mK}$. The length of the actual heating element inside the heating rod was $L_{h r}=900 \mathrm{~mm}$, which started in the stagnant fluid region $45 \mathrm{~mm}$ before the centre of the inlet port position and ended in the stagnant fluid region, $45 \mathrm{~mm}$ after the centre of the outlet port.

Specially machined stepped nylon spacers (shown in Figure 4) were used on either end (inlet and outlet ends) of the inner rod to ensure concentricity of the bright steel rod and the stainless steel tube, and to also contain the aluminium powder. The aluminium powder was used to reduce the radial thermal resistance between the heating wire and the stainless steel tube and was compacted to a uniform density via prolonged vibration. The uniformity of the heat flux on the outer surface of the assembled inner rod (as produced by the internally wound heating wire) was checked before the rod was treated for the thermography technique and placed into the outer acrylic glass tube. This check was conducted during a pre-test in atmospheric air at $22{ }^{\circ} \mathrm{C}$ with a surface heat flux of $11900 \mathrm{~W} / \mathrm{m}^{2}$ using a ThermaCAM E65 thermal camera which had a thermal sensitivity of $0.1{ }^{\circ} \mathrm{C}$ and an absolute accuracy of $\pm 2{ }^{\circ} \mathrm{C}$. It was found that the 
average steady state surface temperature was about $50{ }^{\circ} \mathrm{C}$ and that the largest temperature variation from this was $0.3^{\circ} \mathrm{C}$. Based on this, a heat flux uniformity above $95 \%$ could be guaranteed. The axial heat conduction in the assembled inner rod was also analysed analytically by using the method prescribed by Maranzana et al. [25] for the anticipated range of annular mass flow rates and heat transfer coefficients. Based on this, the maximum ratio of the axial heat conduction to the total heat transfer rate was found to be approximately $0.01 \%$ for cases with the lowest anticipated mass flow rate. Therefore, axial heat conduction was deemed insignificant.

Because the wetted outer surface temperatures of the inner rod were needed to derive the local heat transfer coefficients, a portion of the outer surface of the stainless steel tube was treated with thermochromic liquid crystals (TLCs). The region of interest to this study started $100 \mathrm{~mm}$ downstream from the start of the annulus (shown in Figure 2) and extended an axial distance of $L_{L T C}=660 \mathrm{~mm}$ towards the outlet of the annulus. Several thin layers of paint and protective layers were needed. Firstly, a black base coat was applied to the stainless steel tube and acted as an undercoat which yielded a sufficient and consistent contrasting back colour. It was carefully sprayed onto the stainless steel tube using an airbrush, mounted onto a speed controlled lathe to ensure a smooth and uniform coating. For this purpose the inner rod assembly was carefully rotated and the airbrush (mounted to the tool post of the lathe) was translated along the length of the rod at a predetermined feeding rate. Once the base coat was fully cured, spray-able, water-based TLC-impregnated paint was applied in the same fashion as the base coat. The TLC paint was commercially manufactured by LCR Hallcrest ${ }^{\mathrm{TM}}$ (product code: SPN100 R20C10W2). The paint had an activation temperature of $20{ }^{\circ} \mathrm{C}$, a bandwidth of $10{ }^{\circ} \mathrm{C}$, and a manufacturer's uncertainty of $0.1^{\circ} \mathrm{C}$. This resulted in a measurable temperature range from approximately $20{ }^{\circ} \mathrm{C}$ to $30{ }^{\circ} \mathrm{C}$. 
Because the TLCs were soluble in water, additional care was needed to protect the TLCs from the water flowing in the annulus. For this purpose, transparent self-adhesive polyvinyl chloride (PVC) film was applied along the entire length of the inner rod to produce a watertight seal. A single sheet was wrapped twice around the crystals, to a total thickness of $0.162 \mathrm{~mm}( \pm 10 \mu \mathrm{m})$. Because this protective layer exhibited thermal resistance to the heat transfer from the heating wire to the water in the annulus, the colour response of TLCs would not directly represent the temperature of the wetted surface (which is needed to determine the convection heat transfer coefficient), but rather the temperature on the inside of the PVC layers. Therefore, the effective thermal resistance of the PVC layers had to be carefully measured. This, along with the temperature calibration of the thermography technique are discussed in more detail later in the article.

Once the inner rod was fully assembled and treated, it was placed concentrically inside the acrylic glass outer tube and supported on either end with nylon end-caps and flow passage supports, shown in Figure 4. Therefore, no interfering support systems along the test section length in the annulus were present.

The bulk fluid inlet and outlet temperatures were measured at separate isothermal measuring stations consisting each of a short copper tube onto which eight T-type thermocouples were soldered. No splitter plates were inserted into the measuring stations. The thermocouples were located symmetrically around the copper tube, approximately $45^{\circ}$ apart. To prevent axial heat conduction to these measuring stations, they were insulated from the annular flow passage and other system tubing by means of rubber hoses. A $90^{\circ}$ elbow joint was present upstream from each of the two measuring stations.

The thermocouples and the mass flow meter were connected to a computer data acquisition system that consisted of a National Instruments SCXI-1303 data card, a SCXI-1102 
thermocouple input module and a SCXI-1001 chassis. Their components were connected to a personal computer with LabVIEW software from which the measurements were logged.

At any given moment in time, the majority $(88 \%)$ of the flow passage was covered with elastomeric thermal insulation $(k=0.026 \mathrm{~W} / \mathrm{mK})$ with a thickness of $18 \mathrm{~mm}$. The remaining uncovered sections were kept clear to have a visual line of sight to a portion of the TLCs on the inner surface of the annulus. Based on the material properties of the insulation material and the exposed acrylic glass portion, the maximum heat loss to the laboratory was considered, as will be discussed later. All other portions of the flow loop and the test section were adequately thermally insulation from the laboratory.

\subsection{Imaging mechanism}

An automated imaging mechanism, depicted in Figure 5, was constructed to capture the colour response of the TLCs on the inner rod. The mechanism was designed to position a camera at any desired location along the length and circumference of the test section and was similar to the one used by Van der Westhuizen et al. [22]. It consisted of a stationary frame, onto which the test section was secured, and a moving structure that allowed the camera to be rotated and translated around and along the test section by means of stepper motors.

Images were captured with a 5 megapixel (2 $595 \times 1944$ pixel) Raspberry- $\mathrm{Pi}^{\mathrm{TM}}$ camera module. The focal length of the camera was adjusted to focus on the TLCs. All automatic features of the camera were disabled. Six light-emitting diodes (LEDs) were used to illuminate the TLCs' surface during photography. Each diode was rated 200 lumen and emitting white light at $5500 \mathrm{~K}$. The LEDs were secured symmetrically on either side of the camera to reduce reflections from the outer acrylic glass tube within the viewing frame. 
A Raspberry-Pi ${ }^{\mathrm{TM}} \mathrm{B} 2$ processing unit (a credit-card sized computer) was used to control the stepper motors, camera and LED lighting, which allowed for simple and effective synchronisation between the components.

\subsection{Experimental procedure}

Testing was conducted in a laboratory at night to ensure consistent lighting conditions for calibration and testing [26] and to protect the TLCs, as they are prone to degradation by ultraviolet lighting [27]. Only the LED lights mounted on either side of the camera were used for illumination during the experiments.

Calibration of the thermocouple measuring stations and TLCs' surface was carried out before, as well as after the experiments were conducted. A relationship between the reflected colours of the TLCs and their temperature was needed before surface temperature measurements could be made. This calibration entailed circulating water at specific temperatures $\left(21^{\circ} \mathrm{C}\right.$ to $\left.32{ }^{\circ} \mathrm{C}\right)$ from a Lauda-Proline ${ }^{\mathrm{TM}}$ thermal bath through the annular flow passage and capturing the TLCs' colour response. The temperature of the water in the thermal bath and the flow passage were monitored by the calibrated inlet and outlet measuring stations and a PT100 (uncertainty of $0.1^{\circ} \mathrm{C}$ ) was placed inside the thermal bath.

Once the temperature difference between the inlet and outlet measuring stations were smaller than $0.1{ }^{\circ} \mathrm{C}$ and the PT100 temperature reading did not vary by more than $0.1{ }^{\circ} \mathrm{C}$ for 10 minutes, it was assumed that an isothermal state had been achieved within the test section. The imaging mechanism captured eight images that were spaced $45^{\circ}$ around the circumference of the heating rod for the given isothermal state. More than one axial position were considered to account for possible variations in the colour response field. These variations could be attributed to factors such as diffraction caused by the acrylic glass tube or variations in the distance between the TLCs' surface and the camera. Variations between the reflected colours along the 
length of the TLCs' surface were, however, small (less than $0.06{ }^{\circ} \mathrm{C}$ when translated into temperature along the entire length) and were thus neglected. Therefore, calibration was conducted $240 \mathrm{~mm}$ from the inlet.

From the captured images, a sample area was considered from which the TLCs' colours were extracted. The size and selection of the sample area is considered in a later section of this article. The sample areas were processed and the average colour for the sample area was considered. Because TLCs exhibit a monotonic relationship between hue and temperature, their colours were converted from the red, green and blue (RGB) colour model to the hue, saturation and intensity (HSV) colour model. The hue value also reduces sources of uncertainty, as the hue is no longer a function of brightness [26]. The conversion from the RGB to the HSV colour model was made with Matlab's built-in RBG2HSV function.

A calibration curve was developed by plotting the normalised hue value against its associated PT100 temperature for the temperature range under consideration. This calibration range was chosen as it exhibited a monotonic relationship between the temperature and colour response to eliminate hysteresis issues, as mentioned and recommended by Sabatino et al. [28], and Smith et al. [26]. A typical calibration curve is shown in Figure 6. Here, the crystal temperature is plotted against the normalised hue value $(H)$, which is scaled between 0 and 1 .

The hue-temperature calibration exhibits two definite gradient regions, one region with a relatively small gradient (blue), and another with a relatively steep gradient (orange). Thus, two calibration polynomials were developed for the separate sections on the curve. A sixthorder polynomial was generated for the lower portion of the calibration curve, and a fifth-order polynomial was generated for the upper region to reduce the maximum error between the actual temperature and the temperature calculated from the developed polynomial. The largest absolute error between the PT100 temperature and the estimated temperature was $0.236{ }^{\circ} \mathrm{C}$. 
However, the average effective error that was relevant to this paper was $0.036{ }^{\circ} \mathrm{C}$, with a standard deviation of $0.047^{\circ} \mathrm{C}$. This error was smaller than the uncertainty suggested by Rao and Zang [29] and Rao and $\mathrm{Xu}[30]$ of $0.4{ }^{\circ} \mathrm{C}$ to $0.5^{\circ} \mathrm{C}$ for a single TLC pixel.

After calibration was completed, the main tests of this investigation were conducted. Test Cases A, B and C (on-centre inlets) and Case D (off-centre inlet) were tested with annular Reynolds numbers (based on the hydraulic diameter) ranging from approximately $\operatorname{Re}=2000$ to $\mathrm{Re}=7500$ at $\mathrm{Re}$ increments of approximately 500 . The heat transfer rate for test cases A to D was kept constant at $400 \mathrm{~W}\left(4917 \mathrm{~W} / \mathrm{m}^{2}\right.$ heat flux on the wetted surface) and was carefully selected to match the temperature response of the inner rod to bandwidth of the TLCs. Test sets for geometry cases A to D were designed to investigate turbulent flow scenarios while a $5^{\text {th }}$ test case series, labelled Case E in this article, was used to only verify that turbulent flow cases were indeed covered in Cases $\mathrm{A}$ to $\mathrm{D}$, and that some of the data were not for the transitional flow regime. In this test set, operated with $D_{3}=20 \mathrm{~mm}$, a lower range of mass flow rates were considered from approximately $\mathrm{Re}=200$ to $\mathrm{Re}=2000$ at increments of approximately 200 in an attempt to identify the upper limit of the transitional flow regime. In test set $\mathrm{E}$ it was, however, necessary to alter the heating flux according to the flow rates to best match the inner rod temperature response to the TLCs' bandwidth. The data from this test case does not form part of the main focus of this article and are only used to validate that the main test data was in the turbulent flow regime. Actual achieved Reynolds numbers for the test cases are given in Table 1.

The experimental procedure was divided into three stages; the start-up stage, the data collection stage and the shutdown stage. During start-up, the data acquisition system was switched on and water was circulated through the test section at high flow rates to achieve an overall steady isothermal state for a specific test case. The steady state was assumed to occur once the 
temperature difference between the measuring stations at the inlet and the outlet did not fluctuate by more than $0.1{ }^{\circ} \mathrm{C}$ over a period of five minutes.

During data collection, the positive displacement pump was set to a specific flow rate and the power supply was adjusted to the desired level(s). Once the steady state was reached, the data collection process commenced. The time on the Raspberry- $\mathrm{Pi}^{\mathrm{TM}}$ module and the data-logging computer was synchronised. The imaging mechanism was set to autonomously capture the images around the flow passage.

The camera was moved to its location directly above the inlet and the LED lighting was switched on. The imaging mechanism captured eight images around the circumference of the flow passage at 33 different axial locations. The process was repeated for each flow rate conditions and case type.

For shutdown, the power supply was switched off and the heating rod was allowed to cool. After five minutes, the pumps were switched off and the water was drained from the flow passage.

\section{Data reduction}

\subsection{Inner annular wall thermography}

Wall temperature measurements were made from the hue values extracted from sample areas on the TLC photographs. Due to the sensitivity of the viewing and lighting angles of the TLCs [29], the extracted sample area size was restricted. Small sample areas were favoured, but these areas would increase the time required to photograph the TLCs' surface, as more images would be taken around the flow passage. This was undesirable, as the annulus inlet water temperature tended to drift over time and it was important to keep the time lapse during test runs as short 
as possible. A larger sample area resulted in larger viewing angles. This meant that the extracted hue values and temperatures would not be accurate representations of their true value.

In the study of Van der Westhuizen et al. [22], the influence of the number of images around the circumference of the tube treated with TLCs was considered. They noted that the average circumferential temperature extracted from the sample areas for 40, 20, and 10 photographs around the circumference varied by only $0.04{ }^{\circ} \mathrm{C}$. For this study, it was considered to only make use of eight photographs around the circumference. The difference in the average circumferential temperature for 10 and eight photographs was found to be $0.01{ }^{\circ} \mathrm{C}$, which was considered to be insignificant. Thus, photographs were circumferentially spaced at $45^{\circ}$, which resulted in an arc length of $10.6 \mathrm{~mm}$ on the wetted surface, as shown in Figure 7.

The axial length of the sample area was selected by considering the variation in hue (or calculated temperature) along the length of the TLC sample area during isothermal conditions (by using the calibration data). For a sample length of $40 \mathrm{~mm}$, the variation in temperature in that sample area was $0.77^{\circ} \mathrm{C}$. For a sample length of $20 \mathrm{~mm}$ it was $0.13^{\circ} \mathrm{C}$ and for a sample length of $10 \mathrm{~mm}$ it was $0.067{ }^{\circ} \mathrm{C}$. A large number of data points was needed at the inlet region of the flow passage to capture the boundary layer developed and fewer data points were needed in the thermally developed region. Thus, sample areas with different sample lengths were considered. Twelve sample areas $\left(N_{1}=12\right)$ with a length of $10 \mathrm{~mm}$ were considered for the inlet region, which covered $120 \mathrm{~mm}$ from the centre line of the inlet. Further down the flow passage, a sample length of $20 \mathrm{~mm}$ was considered for the remaining $420 \mathrm{~mm}$ with 21 sample areas $\left(N_{2}=21\right)$. Figure 7 shows the sample areas with their respective sizes.

During heat transfer tests, once the sample area (which is located at the centre of each photograph) was extracted, the average hue value was computed. From this, the temperature for each sample area, $T_{T L C}$, was derived by making use of the TLC calibration polynomials. 
The temperatures of the sample areas were stitched together to obtain a combined temperature field for the inner wall of the annulus.

\subsection{Heat transfer coefficients}

The heat input rate at the inner heated rod, $\dot{Q}_{e l e c}$, is described by equation (1) in terms of the voltage, $V$, and current, $I$, dissipated by the DC power supply.

$$
\dot{Q}_{e l e c}=I V
$$

The actual heat transfer rate to the water, $\dot{Q}_{a}$, is given as:

$$
\dot{Q_{a}}=\dot{m} C_{p}\left(\bar{T}_{\text {bout }}-\bar{T}_{\text {bin }}\right)
$$

Here $m$ is the water mass flow rate as measured by the Coriolis flow meter, $C_{p}$ is the specific heat capacity of the water calculated by the equations proposed by Popiel and Wojtkowiak [31] at the mean bulk fluid temperature based on the inlet and outlet temperature-measuring station, and $T_{\text {bout }}^{-}$and $T_{\text {bin }}^{-}$refer to the arithmetic average temperatures of the eight inlet and eight outlet thermocouples respectively.

The energy balance error, $e b$, is described in equation (3) and is based on $\dot{Q}_{e l e c}, \dot{Q}_{a}$, and the calculated heat loss rate from the water to the laboratory, $\dot{Q}_{l o s s}$ :

$$
e b=\frac{\dot{Q}_{\text {elec }}-\left(\dot{Q}_{a}+\dot{Q}_{\text {loss }}\right)}{\left(\dot{Q}_{\text {elec }}+\dot{Q}_{a}\right) / 2} * 100
$$

As mentioned, additional heat loss through the insulation and acrylic glass tube were mathematically calculated by a first-order approach, with the manufacturers' material properties, the relevant surface areas, and relevant material layer thicknesses. This accounted for between $0.08 \%$ and $1 \%$ of the total heat transfer rate to the water. Once these losses were 
accounted for, the largest energy balance error was found to be $2.56 \%$ with the absolute average energy balance error for all the data presented in this paper being $1.29 \%$.

Since there was a protective PVC layer over the TLCs, the wetted wall temperature $\left(T_{w}\right)$ was different to the temperatures measured by the TLC layer $\left(T_{T L C}\right)$. The temperature difference across the protective layer $\left(\Delta T_{p v c}\right)$ was calculated by multiplying the thermal resistance, $R_{P V C}$ $\left({ }^{\circ} \mathrm{C} / \mathrm{W}\right)$ and the heat transfer rate, $\dot{Q}_{\text {elec }}$ across the protective layer:

$$
\begin{aligned}
& T_{w}=T_{T L C}-\Delta T_{p v c} \\
& \Delta T_{p v c}=\dot{Q}_{e l e c} R_{p v c}
\end{aligned}
$$

$R_{p v c}$ was calculated from experimental data and a one-dimensional heat transfer model similar to the one given in equation (5). For this purpose, recorded TLC temperatures from two case type sets that shared the same heat fluxes, fluid temperatures and fluid flow conditions were compared. The only differing aspect between the two case type sets was the thickness of the PVC protective layer. For the one case type set, two protective sheet layers were considered, while for the other case type set three layers were used. Based on the steady state temperature fields, the differences in the recorded TLC temperatures from the two case type sets could be used to obtain the thermal resistance of a single PVC protective layer. From this the value of $R_{p v c}$ (for two protective sheets) was found to be $0.00494{ }^{\circ} \mathrm{C} / \mathrm{W}$ as obtained from 1584 data points in the two case type sets. The $R_{p v c}$ value included the combined impact of the PVC thermal conductivity and the thickness thereof. Because it is difficult to accurately obtain the thickness of the PVC layers individually, the use of the effective thermal resistance (as installed) was preferred. The experimentally obtained $R_{p v c}$ value was also cross-checked by estimating the thermal resistance based on the total thickness of the PVC layers (approximately $0.162 \mathrm{~mm}$ ) and the reported thermal conductivity of PVC [24], which resulted in a value of 
$0.004996{ }^{\circ} \mathrm{C} / \mathrm{W}$ (which is within $1.06 \%$ of the experimentally obtained value). For data analysis procedures, only the experimentally measured $R_{p v c}$ value was used.

The bulk fluid temperature, $T_{b}(x)$, at any axial position, $x$, is expressed as follows:

$$
T_{b}(x)=\bar{T}_{b i n}+\frac{(x+0.045)}{L_{h s}} \frac{\left(\dot{Q}_{\text {elec }}-\dot{Q}_{\text {loss }}\right)}{\dot{m} C p}
$$

Here $x$ is measured from the centre line of the inlet port and the $45 \mathrm{~mm}$ is included to account for the upstream portion before the inlet port where the heating element started. By assuming a uniform heat loss flux along the heated length of the inner rod $\left(L_{h r}\right)$ a linear increase in bulk fluid temperature along the length of the flow passage is expected.

The local heat transfer coefficient, $h(x)$, on the inner wall of the annular flow passage is expressed as:

$$
h(x)=\frac{\left(\dot{Q}_{e l e c}-\dot{Q}_{\text {loss }}\right) / A_{h r}}{\left(\bar{T}_{w}(x)-T_{b}(x)\right)}
$$

Here the assumed uniform wall heat flux $\left(\dot{Q}_{\text {elec }}-\dot{Q}_{\text {loss }}\right) / A_{h r}$ is based on the heated section of the heating rod surface area where the heat is inserted into the annulus based on the position of the wound heating wire inside the inner rod, $A_{h r}=\pi D_{1} L_{h r}$, and $\bar{T}_{w}$ refers to the averaged arithmetic circumferential temperature of the eight radial locations at a given axial location, $x$.

The local Nusselt number is based on $D_{h}$ is given as:

$$
N u(x)=\frac{h(x) D_{h}}{k}
$$

with $k$ the thermal conductivity of the fluid calculated by the relations proposed by Popiel and Wojtkowiak [31] at the mean bulk fluid temperature between the inlet and outlet measuring stations. 
Because heat transfer correlations report differently on surface averaged heat transfer coefficient, different methods were used to calculate the average heat transfer coefficient. When considering the entire length of the annular duct, the area-weighted heat transfer coefficient for the entire length of the TLC-treated portion from the inlet centre line to the end of the TLC paint (an axial length of $545 \mathrm{~mm}$ ) was calculated as follows:

$$
h_{\text {avg }}=\left(0.5 \sum_{i=1}^{N_{1}} h_{i}+\sum_{i=N_{1}+1}^{N_{1}+N_{2}} h_{i}\right) /\left(0.5 N_{1}+N_{2}\right) \text { for all } x
$$

Here, $h_{i}$ refers to the heat transfer coefficient at sample position $i$. The area-weighted heat transfer coefficients were determined by calculating the average of the local heat transfer coefficients for each sample axial position. Because the sample areas of the first $N_{1}$ number of samples covered an axial length of $10 \mathrm{~mm}$ each and the sample areas of the subsequent $\mathrm{N}_{2}$ number of samples covered an axial length of $20 \mathrm{~mm}$ each, a weighing factor of 0.5 was introduced for the first $N_{1}$ number of samples. It should be noted that the full length of the TLC treated portion could not be used due to the restrictions of the imaging mechanism and the interference of the inlet flexible hoses which only allowed a portion of the heat transfer portion to be photographed.

The length used in this calculations could dramatically influence the obtained average heat transfer coefficients, especially while the flow is thermally developing. In order to perform comparisons with correlations in literature that were developed for longer length heat exchangers, the average heat transfer coefficient for $x \geq 10 D_{h}$ was also calculated as given in equation (10). In this calculation heat transfer coefficients in the traditionally accepted entry length was not taken into consideration. 


$$
h_{\text {avg }}=\left(\sum_{i=N_{1}+2}^{N_{1}+N_{2}} h_{i}\right) /\left(N_{2}-1\right) \text { for } x \geq 10 D_{h}
$$

Here only the last 20 divisions $\left(N_{2}-1\right)$, which each had a width of $20 \mathrm{~mm}$ and which combined spanned the axial positions from $145 \mathrm{~mm}$ to $545 \mathrm{~mm}$ were used.

Drifts in the inlet bulk water temperature were inevitable due to the heat added to the flow loop by the test section (steady drift) and water entering the 1000 -litre reservoir from the cooling loop (fluctuating drift). These temperature drifts were considered and were accounted for by recalculating the local bulk fluid temperature based on the time imprint in the TLC data and the logged inlet bulk fluid data. Thus, the temperature drift was determined by considering the time at which each photo was taken and the drift that had already occurred since the start of the test. Test cases that exhibited a fluctuating temperature profile were not included in the final set of results, since, even though such cases might have reached the steady state at the start of the test, steady-state conditions could not be guaranteed for the entire time span of the test run.

\subsection{Uncertainty analysis}

Errors occurring in measurements and the uncertainties associated with the measured values propagate to the final experimental results. The method by Moffat [32] was used to calculate the uncertainties of the experimental results based on the measurement uncertainties. All uncertainty calculations were based on the uncertainties supplied with the equipment used, equations for the thermophysical properties, and the scatter of the experimental results (where relevant).

Table 2 contains a condensed list of the uncertainties calculated for the experimental results for test case A. The uncertainty of the heat flux, $\delta \dot{q}_{\text {elec }}$, was relatively small due to the accuracy of the measuring equipment and power supply. The uncertainty of the average value of the bulk

fluid temperatures, $\delta \bar{T}_{\text {bin }}$ and $\bar{T}_{\text {bout }}$, was reduced from $0.11{ }^{\circ} \mathrm{C}$ for one thermocouple to 
$0.039{ }^{\circ} \mathrm{C}$ because eight thermocouples were used to measure the temperature at each station. The measuring uncertainty of a single TLC pixel is said to be between $0.4{ }^{\circ} \mathrm{C}$ and $0.5^{\circ} \mathrm{C}$, as suggested by Rao and Zang [29]. However, this was decreased to $0.0015{ }^{\circ} \mathrm{C}$ due to the vast number of pixels in the TLC sample area.

The uncertainty of the thermal resistance of the protective adhesive layer was the largest source of uncertainty of the experimental results with an uncertainty of $8.81 \%$. This uncertainty was due to the scatter in the detected $R_{p v c}$ values as determined from the 1584 data points, and was calculated by considering the standard deviation around the mean of the thermal resistance. The uncertainty of the thermal resistance of the protective adhesive layer was carried over to the temperature difference across the protective adhesive layer. This uncertainty carried the most weight in the uncertainty of the wall temperature and heat transfer coefficients.

The uncertainties of the area-average heat transfer coefficients ranged from $9.2 \%$ to $15.6 \%$ for a Reynolds numbers range of 2041 to 7200 . The uncertainty of the average heat transfer coefficient $\left(\delta h_{\text {avg }}\right)$ increased as Re increased due to the decrease in the temperature difference between $T_{w}$ and $T_{b}$. For the local heat transfer coefficients, uncertainties were largest at the inlets due to smaller temperature differences between $T_{w}$ and $T_{b}$.

\section{Results and discussion}

\subsection{TLC temperature measurements}

The wetted surface temperature field, together with the average circumferential wall temperature for the annular flow passage, is considered in this section.

Figure 8 (a) is a representation of a typical wetted surface temperature field of the annular flow passage for test case $\mathrm{C}$ (on-centre inlet) at $\mathrm{Re}=3500$. The horizontal axis represents the axial distance from the inlet, and the vertical axis represents the radial position around the 
circumference, where $0^{\circ}$ is taken in line with the inlet (thus on top side of the annulus). Unfortunately, the inlet port of the annulus blocked a portion of the view at the inlet region, which resulted in some temperature fields being neglected. These sections are indicated in black.

Considering Figure 8 (a), the inner wall temperature field was approximately symmetric around the circumference and showed a temperature increase along the length. At approximately $x=$ $65 \mathrm{~mm}$ to $115 \mathrm{~mm}$ and $\theta=-45^{\circ}$ to $45^{\circ}$, a relatively warm spot (with respect to the other temperatures in this proximity) was noted due to reduced fluid flow at this location. At the inlet region $(x=0-100 \mathrm{~mm})$, large temperature variations were present around the circumference, which caused impingements of the heat transfer as the fluid flowed around the heating rod.

For the on-centre inlet cases (test cases A, B, C and E), a comparatively symmetric temperature profile was observed. However, when fluid swirl was induced for the off-centre inlet case (test case D), a non-symmetric temperature profile, as seen in Figure 8 (b) was produced. Here, definite warm and cool temperature bands can be seen diagonally across the temperature field. These bands indicate the paths that the swirling fluid followed around the inner rod.

Figure 9 gives the average circumferential wetted surface temperatures along the flow passage for different Reynolds numbers for test case A. Uncertainty error bars are included on the results for $\mathrm{Re}=2561$. The surface temperatures decreased as the flow rate for the experiments increased. The heating rate resulted in wall temperature differences ranging from $1.8^{\circ} \mathrm{C}$ to $6.4{ }^{\circ} \mathrm{C}$ over the length of the flow passage for the different flow rates.

The rate at which the temperatures increased along the length of the flow passage was not constant. Definite disturbances in the temperature-to-distance gradients were present between $x / D_{h}=6$ and 8 , between $x / D_{h}=19$ and 20 , and between $x / D_{h}=28$ and 29. The first disturbance in the trend is the most pronounced. It can be attributed to the effects of flow 
impingement on the inner surface of the annulus. From previous works it has been shown that turbulent impingement flows can result in regions of laminarised flow as the jet dissipates against the impinged surface. For perpendicularly impinged flat surfaces, this causes ringed formations around the impingement point which have reduced local heat transfer coefficients [33]. Compared to a flat impinged surface, the curved nature of the inner wall of an annulus and the bulk motion of the fluid downstream from the inlet, result in more complicated flow patterns in the inlet region of the annular flow passage. However, due to the similarities with the heat transfer coefficient distributions in classical impingement cases, it is believed that the disturbances along the axial length of the heat exchanger are likely caused by the resulting flow patterns which are directly a result of the flow impingement at the inlet.

To confirm that the observed disturbances were not due to local defects in the heated inner rod or the TLCs' painted surface, the surface temperature was reconsidered for a test case for a low flow rate $(\mathrm{Re} \approx 1000)$. For this flow rate, little to very weak disturbances were noted in the surface temperature as is indicated in Figure 9. Because lower flow rates result in lower heat transfer coefficients, higher wall temperatures are experienced, which if localised nonuniform heating was present, would have resulted in more severe wall temperature variations. Therefore, because the measuring technique and precision was not altered in any way, the disturbances observed along the axial direction for higher flow rates are flow rate dependent and are not due to non-uniform heating or faulty temperature measurements. In a separate experimental test, also on an annular duct, but with different geometric sizes and not for uniform heat flux conditions, Van der Westhuizen et al. [22] also observed similar variation in the local heat transfer coefficients in the axial direction. 


\subsection{Local heat transfer coefficients}

In this section the local heat transfer coefficients, expressed as Nusselt numbers, along the length of the annular flow passage are presented and compared to existing correlations and past findings.

Figure 10 presents the local Nusselt numbers for test case A at varying flow rates along a non-dimensional axial length scale. The findings for $h_{i}$ confirm that the heat transfer coefficient decreases from a maximum at the inlet to a relatively constant value further along the length of the flow passage. The high $h_{i}$ at the inlet region is attributed to the absence or development of the boundary layers. Higher Reynolds numbers resulted in a higher $h_{i}$ values.

Related to the temperature distributions, fluctuations in $\mathrm{Nu}$ can be seen. At $x / D_{h} \approx 5$ the Nusselt number exhibits a local minimum, while at $x / D_{h} \approx 8$ it reaches a local maximum followed by a gradual decrease along the length of the flow passage. As mentioned, these fluctuations are probably due to the jet impingement effects.

Turbulent flow theory suggests a hydrodynamic and thermal entry length of $10 D_{h}$ [23]. Based on all the trends in the data in Figure 10, an entry length of approximately $8 D_{h}$ was present. It did not vary significantly for the different turbulent flow rate cases, confirming that the entry length is independent from the flow rate [25]. However, the magnitude of the disturbance in $\mathrm{Nu}$ was larger for higher flow rates.

Shown in Figure 11 are the local $\mathrm{Nu}$ values compared to findings from previous studies as well as the prediction of the Gnielinski correlation [3], which specifically incorporates the entry length into the mathematical formulation. From this correlation the local heat transfer coefficients were derived by implementing the midpoint rule of integration and considering flow passages of different lengths. 
The experimental results from the study of Peyghambarzadeh [34] are for an electrically heated circulated tube and not for an annulus. The results follow the same trend. However, Peyghambarzadeh's local Nusselt numbers were lower by up to $60 \%$ at the inlet region and up to $50 \%$ for $x / D_{h}>10$. Good agreement with the results of Van der Westhuizen et al. [22] was achieved even though they had a hydraulic diameter ratio of $a=0.54$ which was different from the ratio used in this study.

Considering the local heat transfer coefficient, as derived from the correlation of Gnielinski [3], a similar downward trend is visible along the annular flow passage, which confirms the results of the current study. For a lower Reynolds numbers the correlation under-predicts the heat transfer coefficient at the inlet region. However, it predicts the local heat transfer coefficient well for $x / D_{h}>20$. For higher flow rates, the correlation better predicts the heat transfer at the inlet region, but it does not follow the trend for the fully developed heat transfer coefficient.

The heat transfer coefficient findings from this investigation follow the same trend as the results from past studies and correlations. They are also in the same range of results when considering the values of the heat transfer coefficient.

\subsection{Area-weighted average heat transfer coefficients}

The area-weighted average heat transfer coefficients, $h_{a v g}$, for the flow passage are discussed for the entire length of $545 \mathrm{~mm}$ from the inlet.

Figure 12 (a) shows the entire length-wise average Nusselt number values calculated with equation (9) compared against relevant literature sources that also report the combined impact of the developing region and the region there-after for the same axial length. Figure 12 (b) shows the average Nusselt number values calculated with equation (10) for $x / D_{h} \geq 10$ compared against relevant correlations that were developed for longer length heat exchangers 
where the majority of the annular passage length experiences thermally developed flow. These Nusselt numbers also appear in Table 1. As seen, both typed average Nusselt number increases with increasing Reynolds numbers. Considering only the on-centre inlet geometries of the test cases $\mathrm{A}, \mathrm{B}$ and $\mathrm{C}$, it is evident that in Figure 12 (a) their Nusselt numbers are similar in magnitude for Re from 2000 to 4000 while for Re higher than 5 000, the inlet size appeared to have had an influence on $\mathrm{Nu}_{a v g}$, with larger inlet sizes resulting in a higher $\mathrm{Nu}_{\text {avg }}$. A $5 \%$ improvement in the $\mathrm{Nu}_{\text {avg }}$ is evident from test case $\mathrm{B}$ to test case $\mathrm{A}$ and a $10 \%$ improvement is evident from test case $\mathrm{C}$ to test case $\mathrm{A}$ at $\mathrm{Re} \approx 7700$. The average Nusselt number for test cases $\mathrm{A}, \mathrm{B}$ and $\mathrm{C}$ all fall within the same uncertainty band. Considering that the thermal resistance of the protective adhesive layer had the largest influence on the magnitude of the uncertainty and that this protective layer was common to all cases, the magnitude of the average Nusselt number is an actual indication of the influence of the inlet size. Also visible in Figure 12 (a) is a Nusselt number reduction of between $5 \%$ to $23 \%$ from test case $\mathrm{C}$ (on-centre inlet) to test case $\mathrm{D}$ (offcentre inlet), which shared the same inlet size of $10 \mathrm{~mm}$. However, when considering Figure 12 (b) which does not take into account the heat transfer coefficients for $x / D_{h}<10$, little to no difference between the on-centre and off-centre inlet types can be observed. The lack of degradation between cases $\mathrm{C}$ and $\mathrm{D}$ indicates that the reduced Nusselt numbers in Figure 12 (a) are probably due to a reduced influence of impingement for the off-centre inlet configuration which were present only at the inlet region of the annular passage.

The shape of experimentally obtained $\mathrm{Nu}$ over the Re range suggests that the gradient at which $\mathrm{Nu}$ increases tends to decrease with increasing Re. Considering the predictions from existing correlations in Figure 12 (b), McAdams [12] predicts the highest heat transfer rates. This is followed by the correlations of Dittus and Boelter [9], Swamee et al. [21], and Dirker and Meyer [1], which is the most conservative correlation considered. 
The correlations noted in Figure 12 do not capture the drop in gradient of the $\mathrm{Nu}$ in the experimental results for increasing Re values. The experimental results of Van der Westhuizen et al. [22] also noted a decrease in the gradient for $\mathrm{Nu}$ for increasing $\mathrm{Re}$ values. The $\mathrm{Nu}$ values from the study of Van der Westhuizen et al. [22] were between $16 \%$ to $25 \%$ higher than that found in the current investigation. However, the results of Van der Westhuizen et al. [22] was presented with relatively large uncertainties.

\subsection{Upper limit of the transitional flow regime}

The upper limit of the transitional flow regime was investigated from a heat transfer perspective with flow rates in the range of $\mathrm{Re}=204$ to $\mathrm{Re}=7$ 727. Test cases $\mathrm{A}$ and $\mathrm{E}$ (same inlet size) are considered here with 18 intermediate flow rate cases.

In Figure 13, the average Nusselt number obtained via equation (10) is plotted against the Re values on a logarithmic scale on both axes. The different flow regimes can be noted by different gradients. On the graph for $\mathrm{Re}>1000$, the gradient is the steepest, followed by the section for which $\operatorname{Re}<1$ 000. This indicates that the upper limit of the transitional flow regime in this case was at $\operatorname{Re}=1000$. Therefore, it is clear that the data in cases $A$ to $\mathrm{D}$ fall in the turbulent flow regime.

\subsection{Development of heat transfer correlations}

This section deals with the development of a new heat transfer correlation for a concentric annular flow passage in the low turbulent flow regime, which captures the results of this investigation. As noted from existing correlations, heat transfer in a concentric annular flow passage is usually described by the factors $\operatorname{Re}, \operatorname{Pr}, a, f, \mu_{b} / \mu_{w}$ or $T_{b} / T_{w}$ and $D_{h} / L$ to account for the length of the flow passage.

The new correlation was based on the correlation derived by Gnielinski [3] for turbulent flow (for $\operatorname{Re}>10000$ ) in an annular flow passage, as it described the experimental data with relative 
accuracy as documented in sections 4.2 and 4.3. The Gnielinski correlation describes the overall heat transfer. However, to derive the local heat transfer coefficients, annular flow passages with lengths of $x=x_{i} \forall i \in\left[1 ; N_{1}+N_{2}\right]$ were considered and the associative local heat transfer coefficients were derived by means of the integral midpoint rule.

Figure 14 shows the local heat transfer coefficients for test cases A, B and C, and the anticipated $\mathrm{Nu}$ as determined by the new correlation. The new correlations were developed by adapting the entrance correction factor derived by Hausen [15] to be $\left(1+\left(\gamma \frac{D_{h}}{L}\right)^{\frac{2}{3}}\right)$, where $\gamma=$ $34500 /$ Re. In the Gnielinski correlation the term $\varphi=1.07+\frac{900}{R e_{D_{h}}}-\frac{0.63}{1+10 r_{a}}$, as developed by Petukhov and Kirillov [35], was adapted to $\varphi=1.92+\frac{17440}{R e_{D_{h}}}-\frac{0.63}{1+10 \operatorname{Pr}_{a}}$.

The new correlation better predicts the $h_{\text {avg }}$ as opposed to Re by capturing the dip in $h_{\text {avg }}$ with increasing annular flow rates, as noted by the experimental results. $90 \%$ of the predictions fall within the $6 \%$ error bands while all the data is predicted within $10 \%$. This is an improvement on the correlations available in literature. The average error, with reference to the experimentally determined value, was $2.7 \%$ with a standard deviation of $2.5 \%$. This aids with the conclusion that the new correlation successfully captures the experimental results.

$$
\begin{gathered}
N u_{D_{h}}=\frac{\left(\frac{f}{8}\right) \operatorname{Re}_{D_{h}} \operatorname{Pr}_{\mathrm{a}}}{\varphi+12.7 \sqrt{\left(\frac{f}{8}\right)}\left(\operatorname{Pr}_{a}^{\frac{2}{3}}-1\right)}\left(1+\left(\gamma \frac{D_{h}}{L}\right)^{2 / 3}\right) F_{a n n} K \\
\gamma=\frac{34500}{\operatorname{Re}} \\
\varphi=1.92+\frac{17440}{\operatorname{Re}_{D_{h}}}-\frac{0.63}{1+10 \operatorname{Pr}_{a}}
\end{gathered}
$$




$$
\begin{gathered}
K=\left(\frac{\operatorname{Pr}_{a}}{\operatorname{Pr}_{i w}}\right)^{0.11} \\
F_{a n n}=0.75 a^{-0.17} \\
f=\left(1.8 \log _{10} \operatorname{Re}^{*}-1.5\right)^{-2} \\
\operatorname{Re}^{*}=\operatorname{Re}_{D_{h}} \frac{\left(1+a^{2}\right) \ln a+\left(1-a^{2}\right)}{(1-a)^{2} \ln a}
\end{gathered}
$$

The newly developed correlation is based on data for $a=0.648, D_{h}=14.8 \mathrm{~mm}, 10 \mathrm{~mm}<D_{3}$ $<20 \mathrm{~mm}, 2000<\operatorname{Re}<7500, L / D_{h}>2$ and $6.0<\operatorname{Pr}_{a}<7.0$ for on-centre cases, excluding the off-centre case. 


\section{Conclusion}

Local heat transfer coefficients were captured for the inlet region of a concentric annular flow passage by means of temperature measurements made by TLCs. The absence of boundary layers at the inlet region of a concentric tube heat exchanger results in an increase in heat transfer ability.

The detailed wall temperature fields gave an indication of fluid flow for the different inlets studied in this investigation. Local heat transfer coefficients were derived from the wall temperatures and indicated boundary layer development. The local heat transfer coefficients decreased from a maximum at the inlet to a minimum steady value beyond fully developed flow. A disturbances in the local maximum and minimum values for the heat transfer coefficients are likely due to the inlet flow impingement onto the inner annular wall.

The size of the inlet does not have a major influence on the overall heat transfer for low flow rate cases of Reynolds numbers between 2000 and 4 000. For high flow rate cases, a large inlet is favoured, which leads to higher overall heat transfer coefficients. It was shown that swirl flow, as produced by the off-centre inlet type, resulted in a significant reduction in the heat transfer coefficient in the inlet region. A new correlation was developed to better suit the experimental data which estimates the area-weighted heat transfer coefficients noted in this study. 


\section{Acknowledgements}

The National Research Foundation of South Africa provided funding for this project. 


\section{References}

1. J. Dirker, J.P. Meyer, Convective heat transfer coefficients in concentric annuli. Heat Transfer Engineering 26(2) (2005) $38-44$.

2. H.A. Mohammed, A. Campo, R. Saidur, Experimental study of forced and free convective heat transfer in the thermal entry region of horizontal concentric annuli. International Communications in Heat and Mass Transfer 37(7) (2010) 739 - 747.

3. V. Gnielinski, Heat transfer coefficients for turbulent flow in concentric annular ducts. Heat Transfer Engineering 30(6) (2009) 431 - 436.

4. W.R. Van Zyl, J. Dirker, J.P. Meyer, Single-phase convective heat transfer and pressure drop coefficients in concentric annuli. Heat Transfer Engineering 34 (13) (2013) 1112 1123.

5. F.P. Prinsloo, J. Dirker, J.P. Meyer. Heat transfer and pressure drop characteristics in the annuli of tube-in-tube heat exchangers (horizontal lay-out), Proceedings of the 15th International Heat Transfer Conference, Kyoto (2014), paper IHTC15-9225. 2014.

6. A. Quarmby, R.K. Anand, Turbulent heat transfer in the thermal entrance region of concentric annuli with uniform wall heat flux, International Journal of Heat and Mass Transfer 13 (2) (1970) $395-411$.

7. Y. Lee, Turbulent heat transfer from the core tube in thermal entrance regions of concentric annuli. International Journal of Heat and Mass Transfer 11(3) (1968) 509 522.

8. A. Quarmby, Some measurements of turbulent heat transfer in the thermal entrance region of concentric annuli. International Journal of Heat and Mass Transfer 10 (3) (1967) $267-276$. 
9. F.W. Dittus, L.M.K. Boelter, Heat transfer in automobile radiators of the tubular type. University of California Publications on Engineering 2 (13) (1930) $443-461$.

10. E.N. Sieder, G.E. Tate, Heat transfer and pressure drop of liquids in tubes. Industrial \& Engineering Chemistry 28 (12) (1936) 1429 - 1435.

11. L. Prandtl, Führer Durch Die Strömungslehre, 1942.

12. W. H. McAdams, Heat Transmission. 3rd edition, New York, 1954.

13. V. Gnielinski, New equations for heat and mass transfer in turbulent pipe and channel flow, International Journal of Chemical Engineering 16(2) (1976) $359-368$.

14. W. Nusselt, Der Wärmeaustausch zwischen Wand und Wasser im Rohr. Forschung auf dem Gebiet des Ingenieurwesens A 2(9) (1931) 309 - 313.

15. H. Hausen, Darstellung des warmeuberganges in rohren durch verallgemeinerte potenzbeziehungen. Z. VDI Beih. Verfahrenstech, 1943. 4(4).

16. M. Bhatti, R. Shah, Turbulent and transition flow convective heat transfer in ducts, Handbook of single-phase convective heat transfer, 1987, pp. $4.1-4.166$.

17. R.F. Badus'haq, Forced-convection heat transfer in the entrance region of pipes. International Journal of Heat and Mass Transfer 36 (13) (1993) 3343 - 3349.

18. J.G. Christie, Transport Processes and Unit Operations. Prentice-Hall International, 1993: pp. $393-397$.

19. A.J. Ghajar, L.-M. Tam, Heat transfer measurements and correlations in the transition region for a circular tube with three different inlet configurations, Experimental Thermal and Fluid Science 8 (1) (1994) 79 - 90. 
20. K. Gasljevic, E. Matthys, Experimental investigation of thermal and hydrodynamic development regions for drag-reducing surfactant solutions. Transactions-American society of mechanical engineers journal of heat transfer 119 (1997) $80-88$.

21. P. K. Swamee, N. Aggarwal, V. Aggarwal, Optimum design of double pipe heat exchanger. International Journal of Heat and Mass Transfer 51 (9-10) (2008) 2260 2266 .

22. J.E. Van der Westhuizen, J. Dirker, J.P. Meyer, Implementation of Liquid Crystal Thermography to Determine Wall Temperatures and Heat Transfer Coefficients in a Tube-in-tube Heat Exchanger, Experimental Heat Transfer 29 (2016) 632 - 656.

23. Y.A. Çengel, A.J. Ghajar, Heat and mass transfer: fundamentals \& applications. 2011: McGraw-Hill.

24. W.D. Callister, D.G. Rethwisch, Materials science and engineering: an introduction. Vol. 7. 2007: Wiley New York.

25. Maranzana G, Perry, I. and Maillet D., Mini- and micro-channels: influence of axial conduction in the walls, International Journal of Heat and Mass Transfer 47 (2004) 3993 -4004 .

26. C.R. Smith, D.R. Sabatino, and T.J. Praisner, Temperature sensing with thermochromic liquid crystals, Experiments in Fluids 30 (2) (2001) 190 - 201.

27. Hallcrest, TLC products for use in research and testing applications_Hallcrest, Hallcrest, Editor. 2014, Hallcrest: Glenview. 
28. D.R. Sabatino, T.J. Praisner, and C.R. Smith, A high-accuracy calibration technique for thermochromic liquid crystal temperature measurements. Experiments in Fluids 28 (6), (2000) $497-505$.

29. Rao, Y. and S. Zang, Calibrations and the measurement uncertainty of wide-band liquid crystal thermography. Measurement Science and Technology 21(1) (2010) Article number: 015015

30. Rao, Y. and Y. Xu, Liquid crystal thermography measurement uncertainty analysis and its application to turbulent heat transfer measurements, Advances in Condensed Matter Physics 2012 (2012) Article number: 898104

31. C. Popiel, J. Wojtkowiak, Simple formulas for thermophysical properties of liquid water for heat transfer calculations (from $0^{\circ} \mathrm{C}$ to $150^{\circ} \mathrm{C}$ ), Heat transfer engineering $19(3)$, (1998), $87-101$.

32. R.J. Moffat, Describing the uncertainties in experimental results, Experimental thermal and fluid science 1(1) (1988) 3 - 17 .

33. T. J. Craft, Graham L.J.W., Launder B.E., Impingement jet studies for turbulence models assessment-II. An examination of the performance of four turbulence models, International Journal of Heat and Mass Transfer 36 (1993) 2685 - 2697.

34. S. Peyghambarzadeh, Forced Convection Heat Transfer in the Entrance Region of Horizontal Tube under Constant Heat Flux, World Applied Sciences Journal 15(3) (2011) $331-338$.

35. B.S. Petukhov, V.V. Kirillov, On heat exchange at turbulent flow of liquid in pipes. Teploenergetika 4 (4) (1958) 63 - 68. 
Nomenclature

\begin{tabular}{|c|c|}
\hline$A$ & $\operatorname{area}\left(\mathrm{m}^{2}\right)$ \\
\hline$a$ & annular ratio \\
\hline$C p$ & specific heat $(\mathrm{J} / \mathrm{kgK})$ \\
\hline$D$ & diameter (m) \\
\hline$e b$ & energy balance $(\%)$ \\
\hline$f$ & friction factor \\
\hline$h$ & heat transfer coefficient $\left(\mathrm{W} / \mathrm{m}^{2} \mathrm{~K}\right)$ \\
\hline$H$ & normalised hue \\
\hline$I$ & electric current (A) \\
\hline$K$ & correlation constant \\
\hline$k$ & thermal conductivity $(\mathrm{W} / \mathrm{mK})$ \\
\hline$L$ & length (m) \\
\hline$\dot{m}$ & mass flow rate $(\mathrm{kg} / \mathrm{s})$ \\
\hline$N_{1}$ & number of small sample areas \\
\hline$N_{2}$ & number of larger sample areas \\
\hline $\mathrm{Nu}$ & Nusselt number \\
\hline $\operatorname{Pr}$ & Prandtl number \\
\hline$\dot{Q}$ & heat transfer rate $(\mathrm{W})$ \\
\hline$q^{\prime \prime}$ & heat flux $\left(\mathrm{W} / \mathrm{m}^{2}\right)$ \\
\hline$R$ & thermal resistance $\left({ }^{\circ} \mathrm{C} / \mathrm{W}\right)$ \\
\hline $\operatorname{Re}$ & Reynolds number \\
\hline $\mathrm{Re}^{*}$ & modified Reynolds number \\
\hline$T$ & temperature $\left({ }^{\circ} \mathrm{C}\right)$ \\
\hline$V$ & electric voltage (V) \\
\hline$x$ & axial location from the inlet $(\mathrm{m})$ \\
\hline
\end{tabular}




\section{Greek symbols}

$\begin{array}{ll}\gamma & \text { correlation constant } \\ \Delta & \text { change in entity } \\ \delta & \text { uncertainty } \\ \theta & \text { radial position } \\ \mu & \text { dynamic viscosity }(\mathrm{kg} / \mathrm{ms}) \\ \varphi & \text { correlation constant }\end{array}$

\section{Subscripts}

$a$

avg

$b$

bin

bout

elec

$h$

$h r$

$i$

$p v c$

$T L C$

w

wS

1

2

3

annular

area-weighted average

bulk fluid

bulk fluid inlet

bulk fluid outlet

electric

hydraulic

heated rod

local axial location

protective adhesive layer

thermochromic liquid crystals

wall

wetted surface

inner annular wall

outer annular wall

inlet or outlet diameter 


\section{Abbreviations}

HSV Hue, Saturation and Intensity

LCT Liquid crystals thermography

LED Light-emitting diode

RGB Red, Green and Blue

TLC Thermochromic liquid crystals 


\section{List of figures}

Figure 1: Experimental facility

Figure 2: Schematic view of test section

Figure 3: An isometric section view of the test section

Figure 4: An isometric view of the annular flow passage

Figure 5: The imaging mechanism

Figure 6: The hue-to-temperature calibrations

Figure 7: The sample areas considered

Figure 8: Wall temperature field for $\operatorname{Re} \approx 3500, q^{\prime \prime}=4700 \mathrm{~W} / \mathrm{m}^{2}$ : a) Case C (on-centre); b) Case D (off-centre)

Figure 9: The average circumferential wall temperatures for varying flow rates for test case A

Figure 10: Local Nusselt numbers for test case A for a number of flow rates

Figure 11: Local Nusselt numbers compared to previous findings

Figure 12: Comparison of experimental results with literature for (a) the entire length using

$$
\text { equation (9) and (b) for } x / D_{h}>10 \text { using equation (10) }
$$

Figure 13: Upper limit of the transitional flow regime

Figure 14: Local Nusselt numbers from experimental results and the developed correlation 


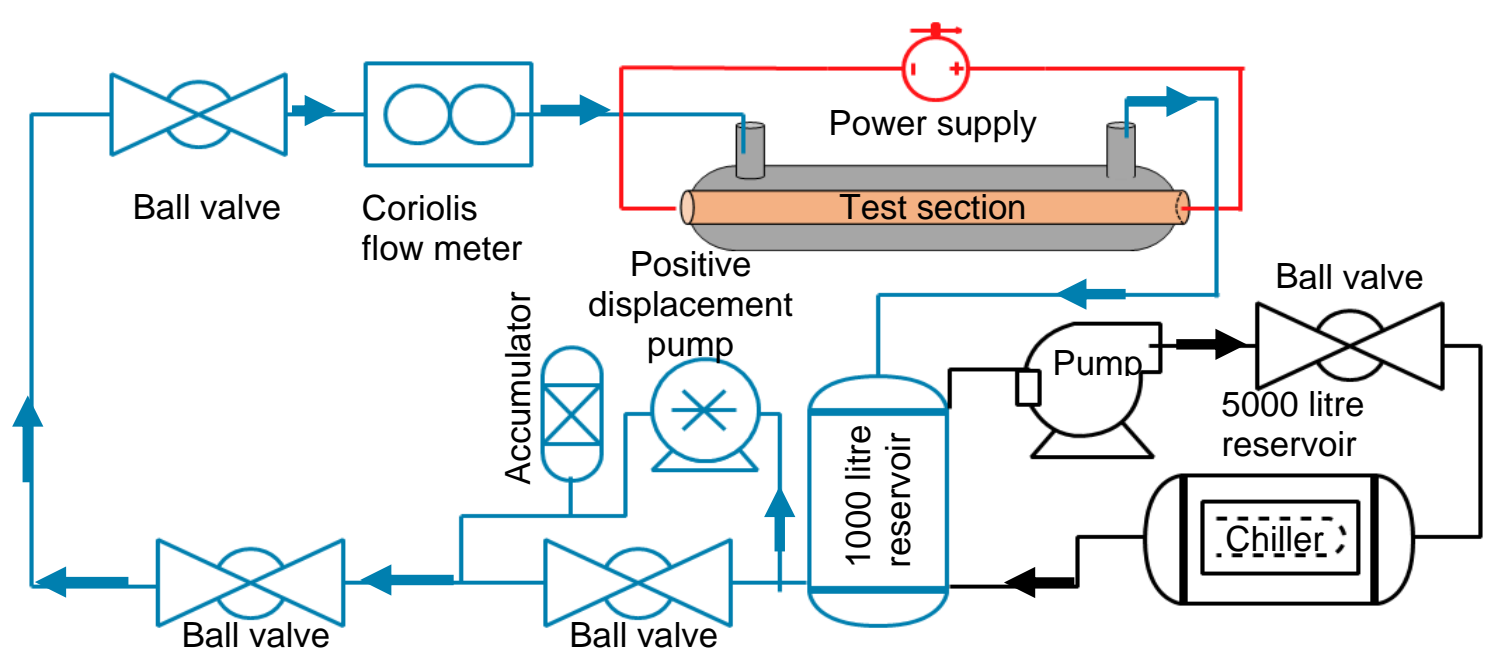

Figure 1: Experimental facility 


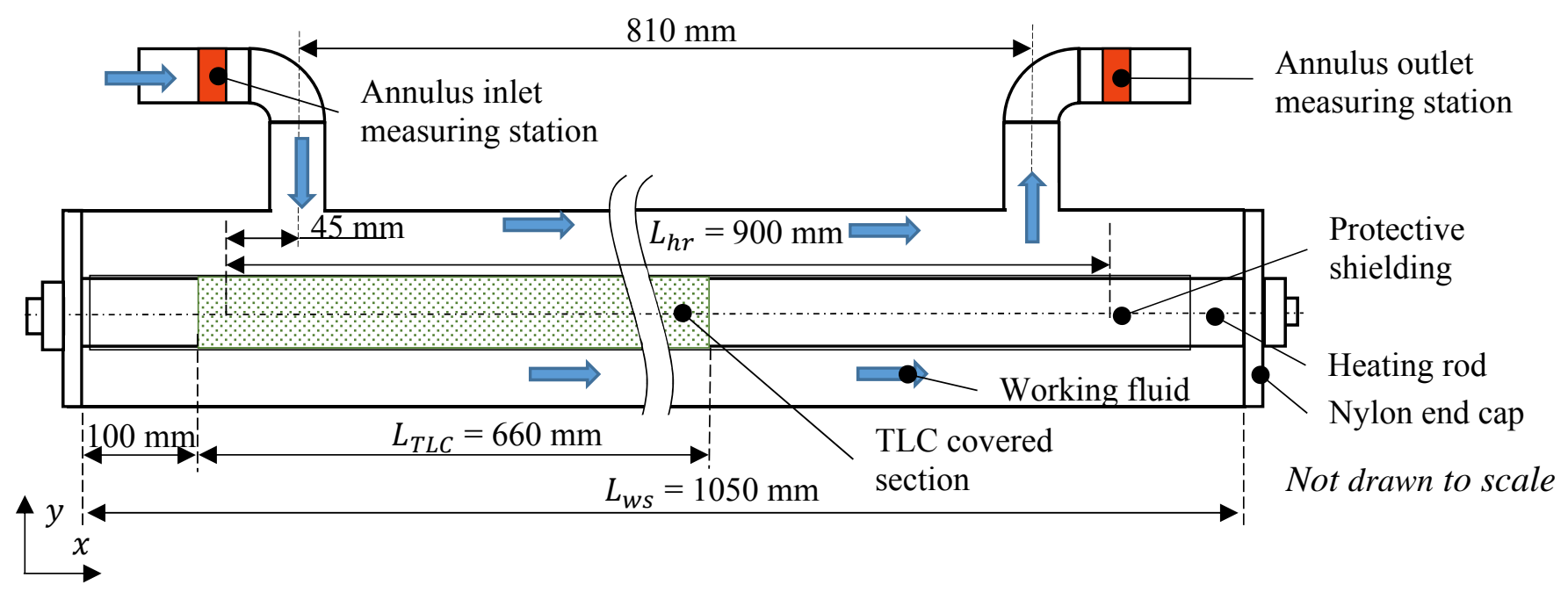

Figure 2: Schematic view of test section 


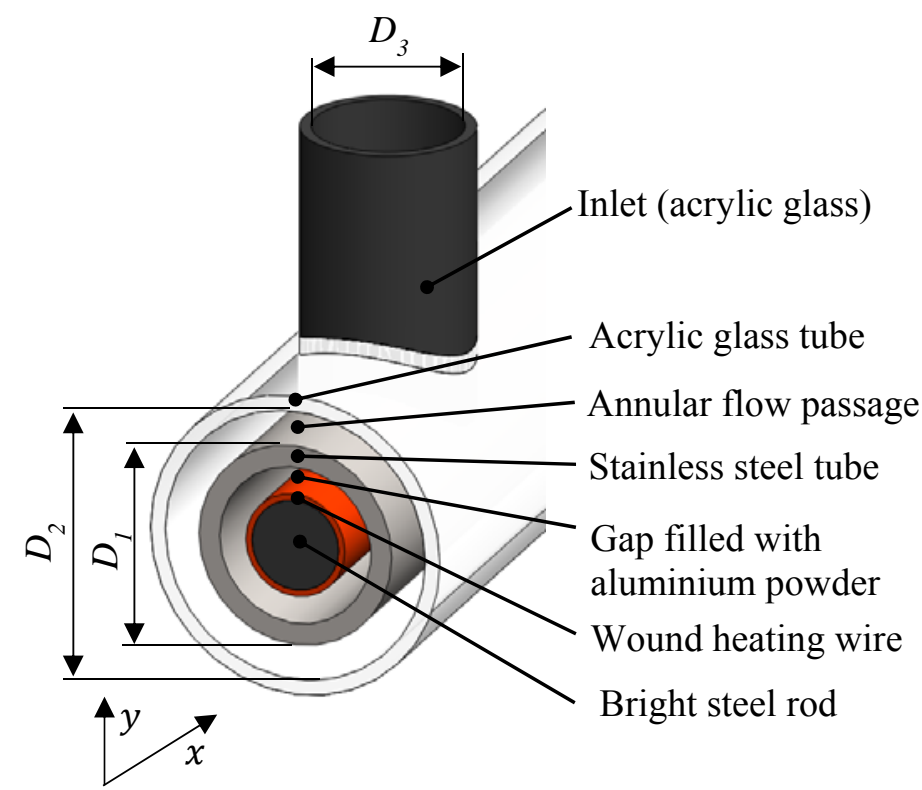

Figure 3: An isometric section view of the test section 


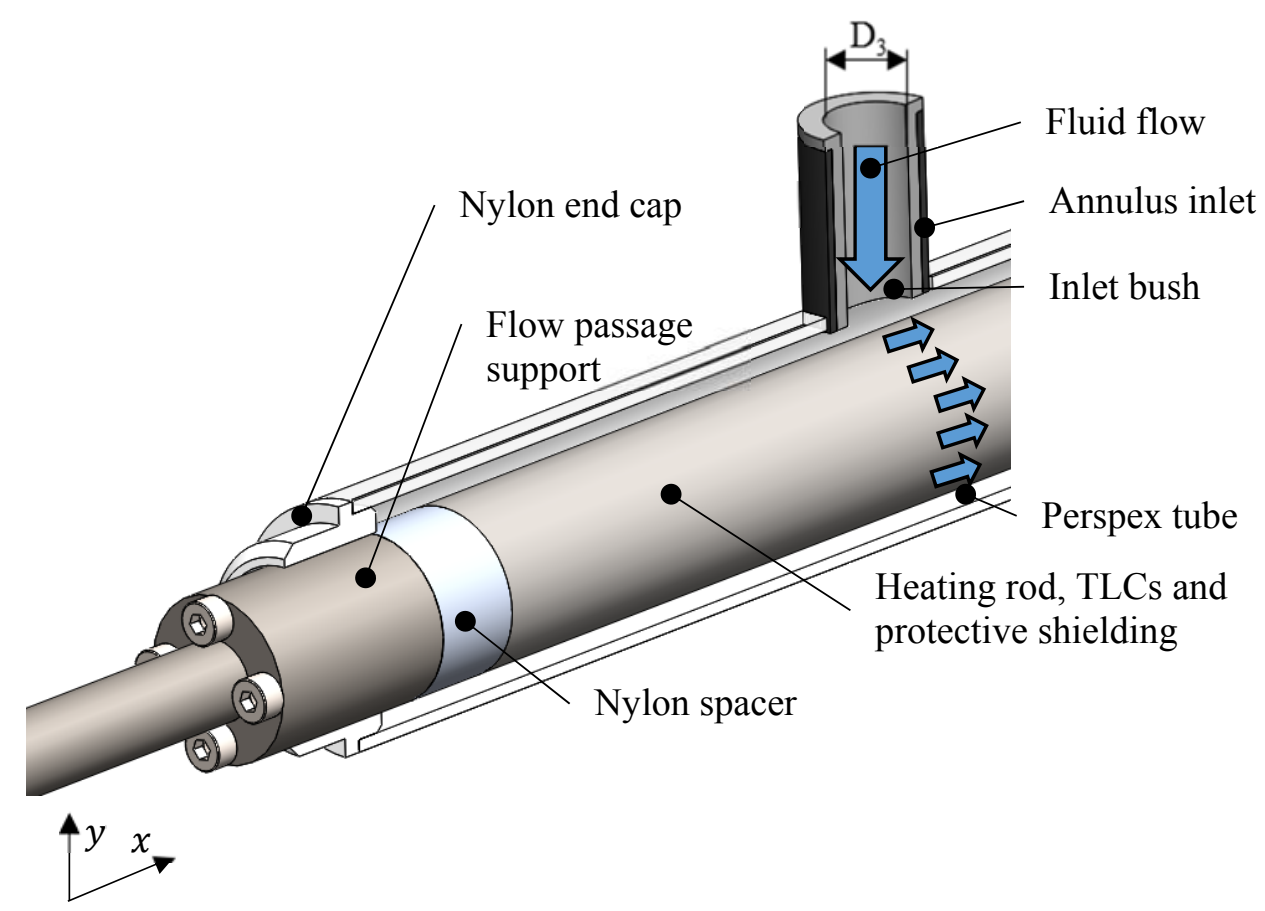

Figure 4: An isometric view of the annular flow passage 


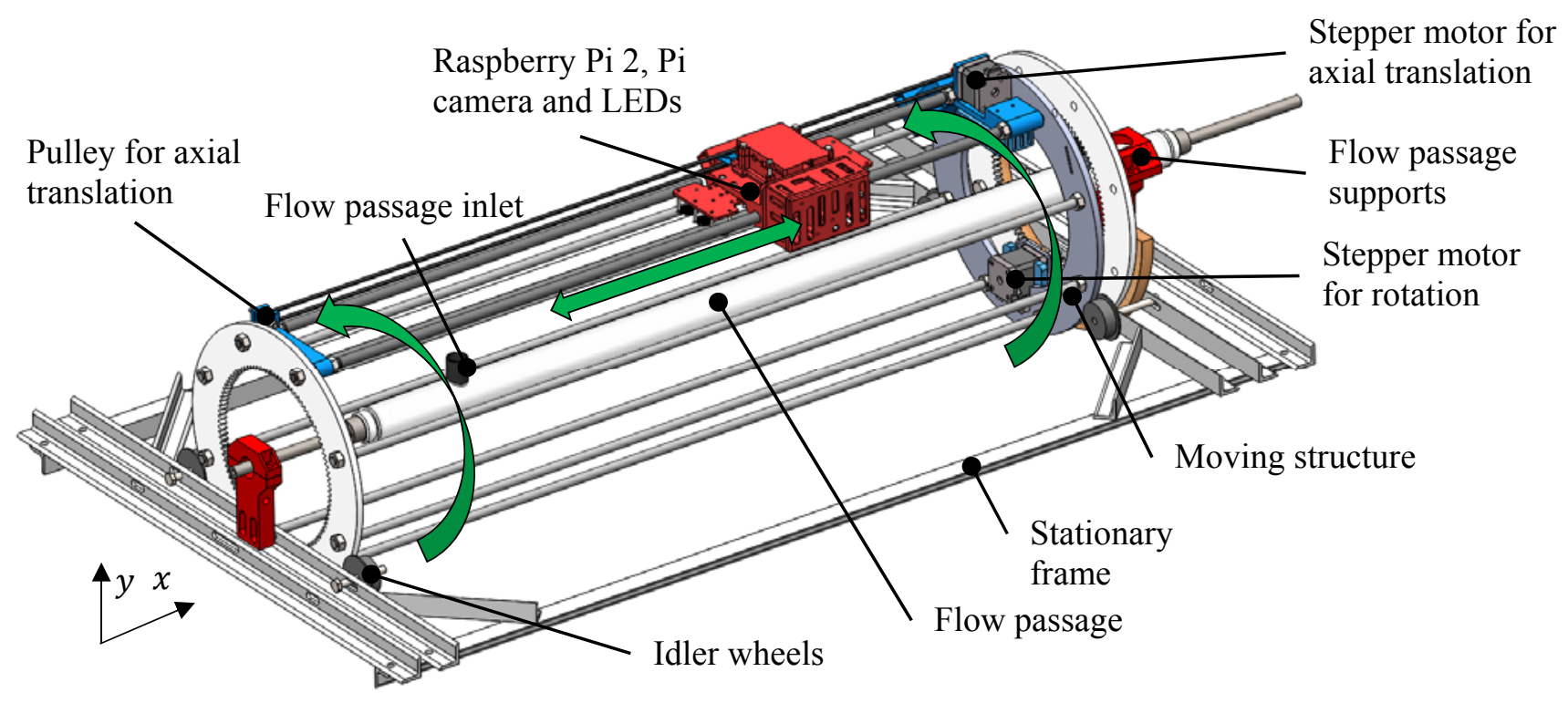

Figure 5: The imaging mechanism 


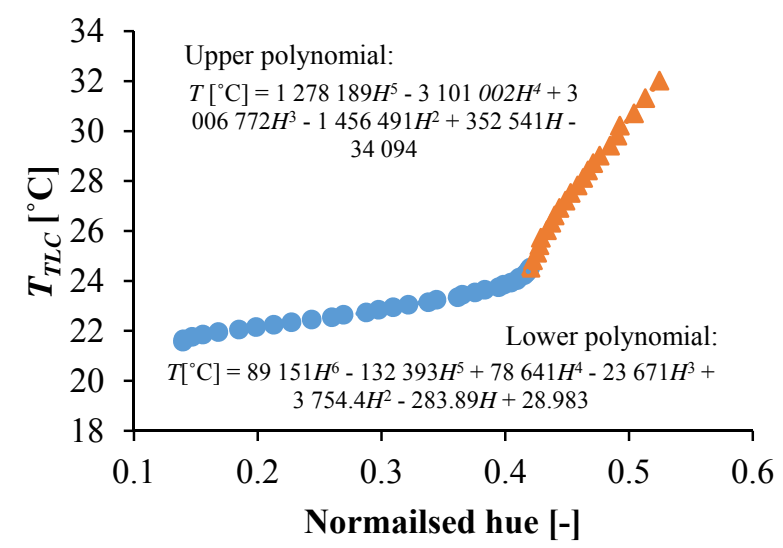

Figure 6: The hue-to-temperature calibrations 

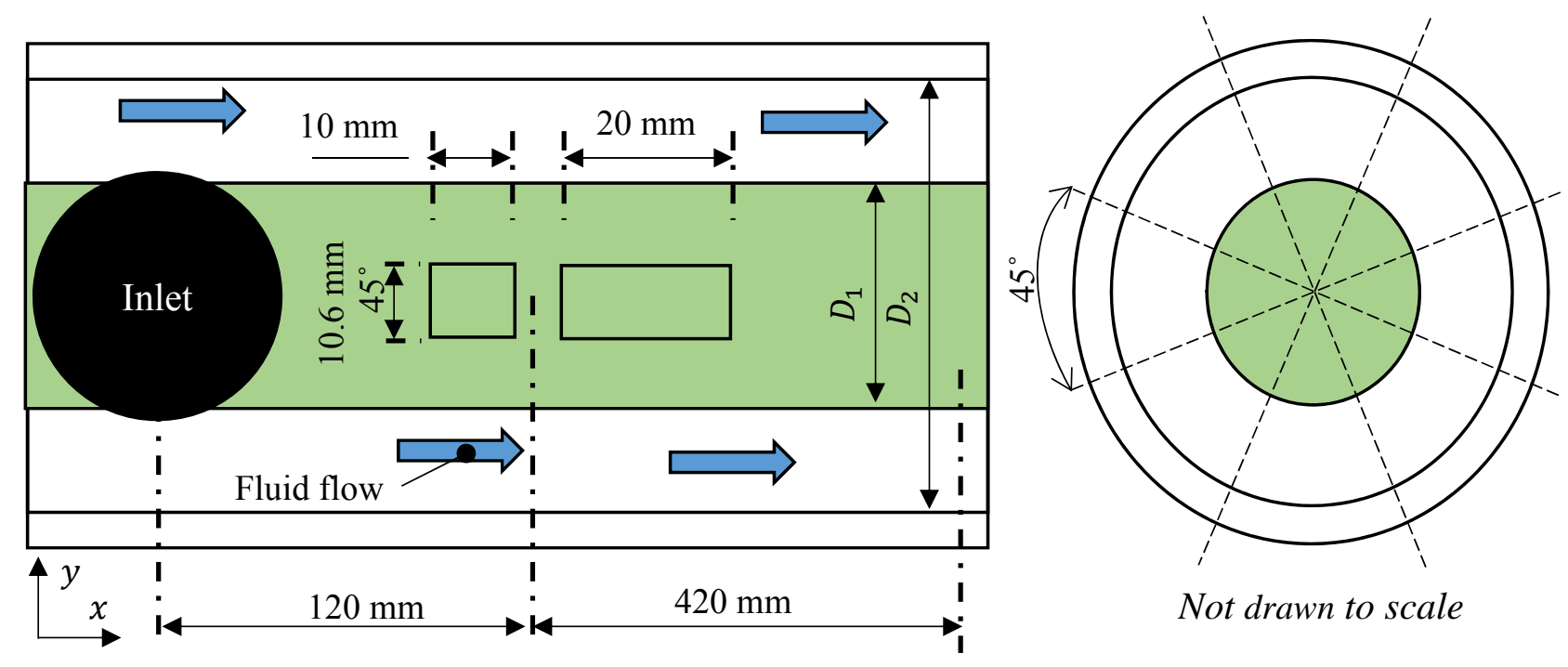

Not drawn to scale

Figure 7: The sample areas considered 


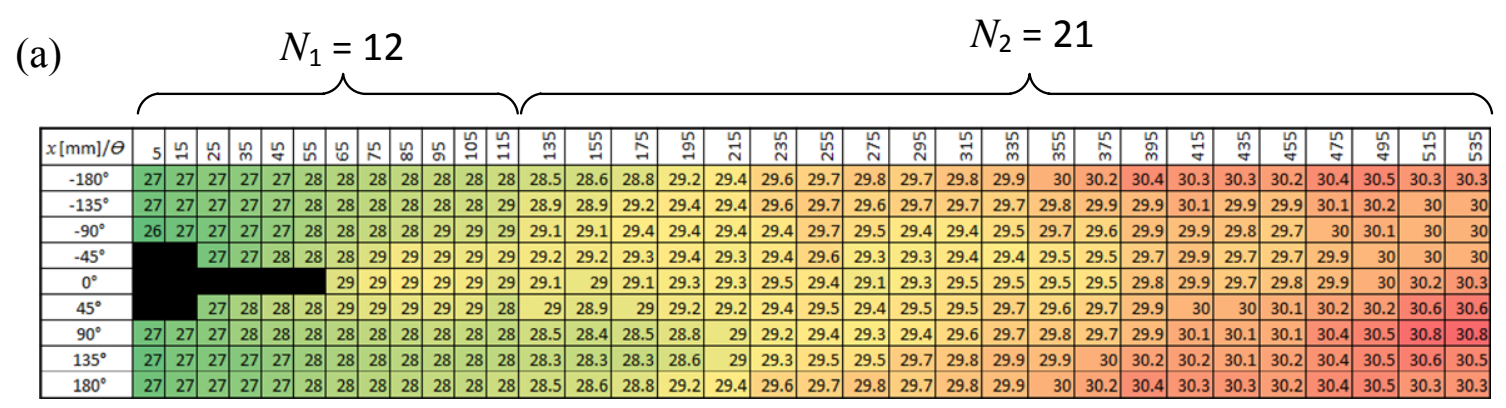

(b)

\begin{tabular}{|c|c|c|c|c|c|c|c|c|c|c|c|c|c|c|c|c|c|c|c|c|c|c|c|c|c|c|c|c|c|c|c|c|c|}
\hline & & $\cong$ & ఓૂ & m & & นn & $\stackrel{0}{0}$ & 乞 & $\stackrel{\infty}{\infty}$ & 요 & 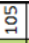 & $\exists$ & m & ્ِન & $\hat{\exists}$ & $\stackrel{-\sigma}{2}$ & $\stackrel{\mathbb{N}}{\mathrm{N}}$ & $\stackrel{\sim}{N}$ & $\stackrel{\text { N }}{N}$ & $\stackrel{n}{\sim}$ & ని & $\vec{m}$ & $\stackrel{m}{m}$ & ल्री & m & लू & $\vec{F}$ & 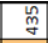 & 号 & $\begin{array}{ll}\stackrel{n}{N} \\
\forall\end{array}$ & 号 & जี & 岕 \\
\hline & 27 & 27 & & & & & & & & & & & 8.8 & 8.8 & 28.9 & 29.1 & 29.8 & 30.3 & 30.7 & 31.0 & 31.4 & 31.3 & 30.9 & 30.4 & 30.3 & 30.3 & 30.5 & 30.5 & 30.8 & 30.9 & 31.1 & 31.0 & 31. \\
\hline & & 27 & & & & & & & & & & & 7.7 & 5 & & .3 & 29.7 & 30.2 & 0.6 & 0.8 & .8 & 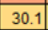 & .8 & .5 & 8 & 30.2 & 0.2 & 0.3 & 0.5 & 0.7 & 1.0 & 1.1 & 1. \\
\hline & 26 & 27 & & 20 & & 28 & & & 28 & 28 & 2 & & 3.2 & 4 & & 2 & .5 & 2 & 4 & 0.0 & .7 & 9.5 & 3 & 9.6 & 9.9 & 30.2 & 0.3 & 0.3 & 0.7 & 1.0 & 1.1 & & 31.3 \\
\hline & & & & 27. & 27 & 28 & & & 28 & 28 & 28 & 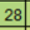 & 28.2 & 28.8 & 4 & .4 & 29.9 & 30.5 & 30.3 & 29.6 & .3 & .3 & 7 & 9.8 & 30.2 & 30.6 & 30.7 & 30.8 & 1.1 & 37.3 & & & 1. \\
\hline & & & & & & & & 28 & 28 & 28 & 2 & 28 & 28.7 & 29.0 & 29.5 & 9 & 30.5 & 30.5 & 29.9 & 29.4 & 9.5 & 0.0 & 2 & 30.4 & 30 & 31.4 & 11.3 & 1.6 & 31.6 & 31.5 & 31.6 & 31.4 & 31. \\
\hline & & & 27 & 2 & & 28 & 28 & 8 & 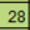 & 28 & 2 & 29 & 29.1 & 29.3 & 30.1 & 30.4 & 30.6 & 30.3 & 9.8 - & 0.1 & 4 & 30.9 & 31.2 & 31.3 & $\begin{array}{l}31.7 \\
\end{array}$ & 32.1 & 32.2 & 31.9 & 31.7 & 31.3 & 31.3 & 31.5 & 31.7 \\
\hline & & 27 & 27 & 28 & 28 & 88 & 2 & 28 & 28 & 28 & 2 & 29) & 29.0 & 29.3 & 29.8 & .0 & 29.6 & 29.8 & 30.4 & 30.7 & 1.4 & 31.8 & 32.1 & 32.1 & 7 & 32 & 31.7 & 31.0 & 31.1 & 31.2 & 31.5 & 31.8 & 32.0 \\
\hline & 27 & 27 & & 27 & & 28 & & & 20 & 28 & 2 & 29 & 28.8 & 29.0 & 29.2 & 28.9 & a & 30 & 30.6 & 31.0 & .6] & 32.1 & 32.2 & \begin{tabular}{|c|}
31.8 \\
\end{tabular} & 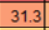 & 31.0 & 0.6 & 30.3 & 30.8 & 31.1 & 31.3 & 31.5 & 31. \\
\hline & 27 & \begin{tabular}{|l|}
27 \\
\end{tabular} & 21 & 27 & & 8 & 2 & 28 & 2 & 28 & & 29 & 28.8 & 28.8 & & 1 & 29.8 & 30.3 & 30.7 & 31.0 & 1.4 & 1.3 & 30.9 & 0.4 & $t$ & 30.3 & 30.5 & 0.5 & 0.8 & 30.9 & 31.1] & 31.0 & \\
\hline
\end{tabular}

Figure 8: Wall temperature field for $\operatorname{Re} \approx 3500, q^{\prime \prime}=4700 \mathrm{~W} / \mathrm{m}^{2}$ : a) Case $C$ (on-centre); b) Case D (off-centre) 


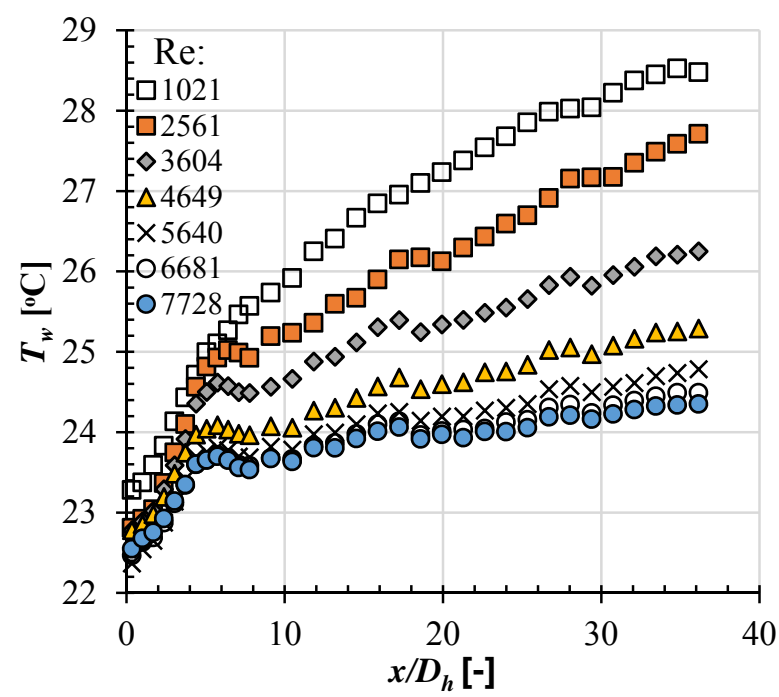

Figure 9: The average circumferential wall temperatures for varying flow rates for test case A 


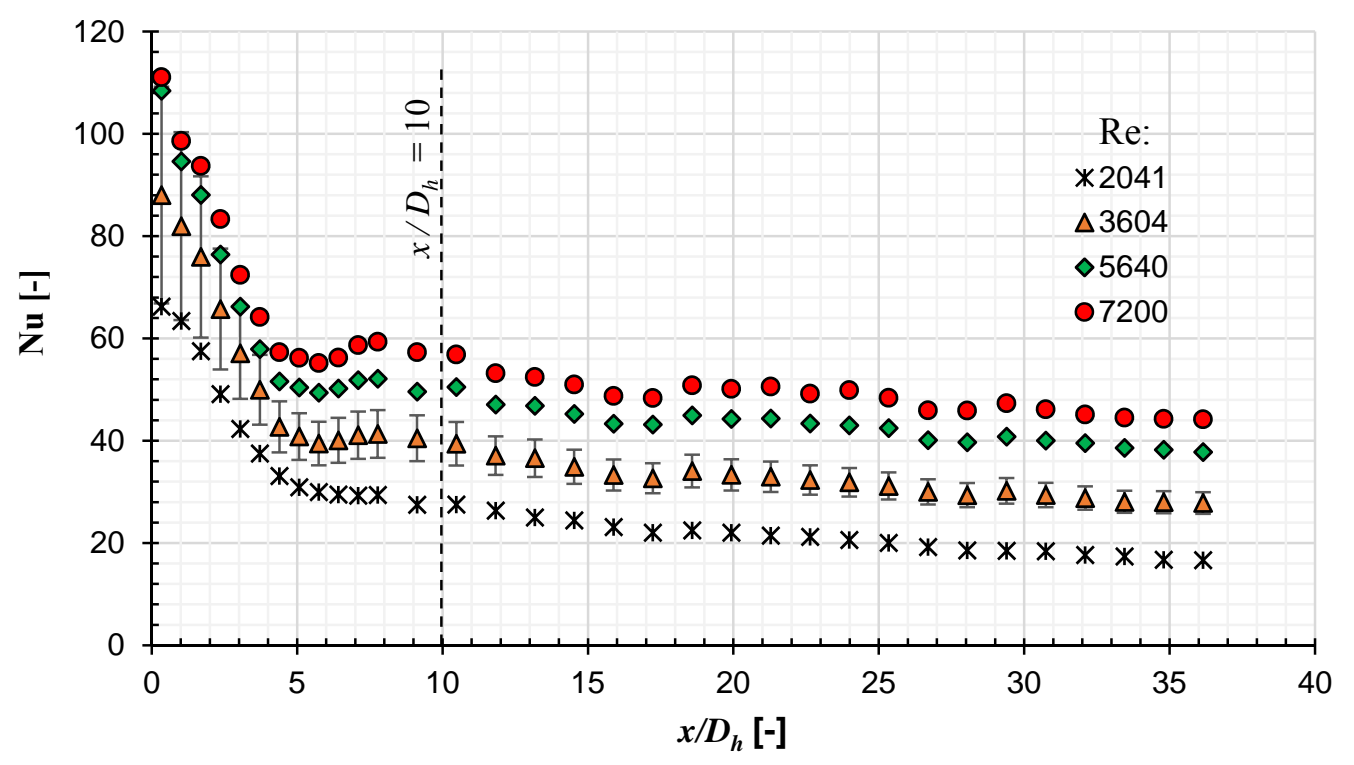

Figure 10: Local Nusselt numbers for test case $A$ for a number of flow rates 


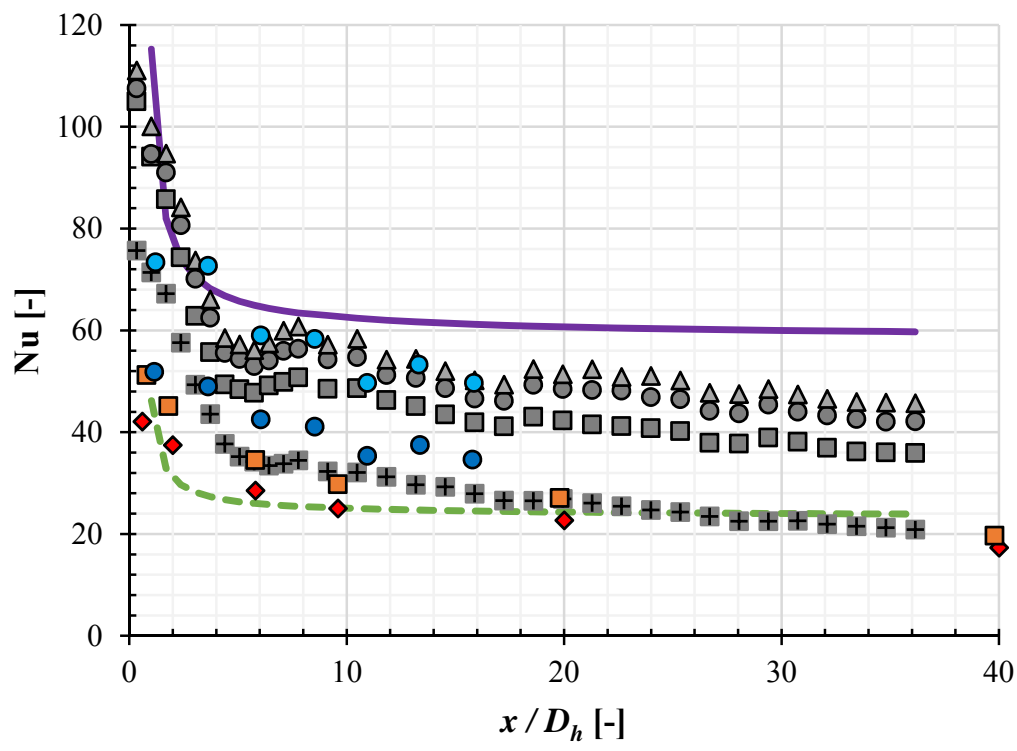

Figure 11: Local Nusselt numbers compared to previous findings
Current study

$$
\begin{array}{ll} 
\pm & \mathrm{Re}=2561 \\
\square & \mathrm{Re}=5129 \\
\text { ○ } & \mathrm{Re}=6781 \\
\Delta & \mathrm{Re}=7727
\end{array}
$$

Peyghambarzaden [34]

$\diamond \quad \operatorname{Re}=6500$

ㅁ $\operatorname{Re}=8500$

Van der Westhuizen et al. [22]

○ $\mathrm{Re}=2500$

○ $\operatorname{Re}=5000$

Gnielinski [3]

- - $\cdot \operatorname{Re}=2561$

$\longrightarrow \mathrm{Re}=7727$ 
(a)

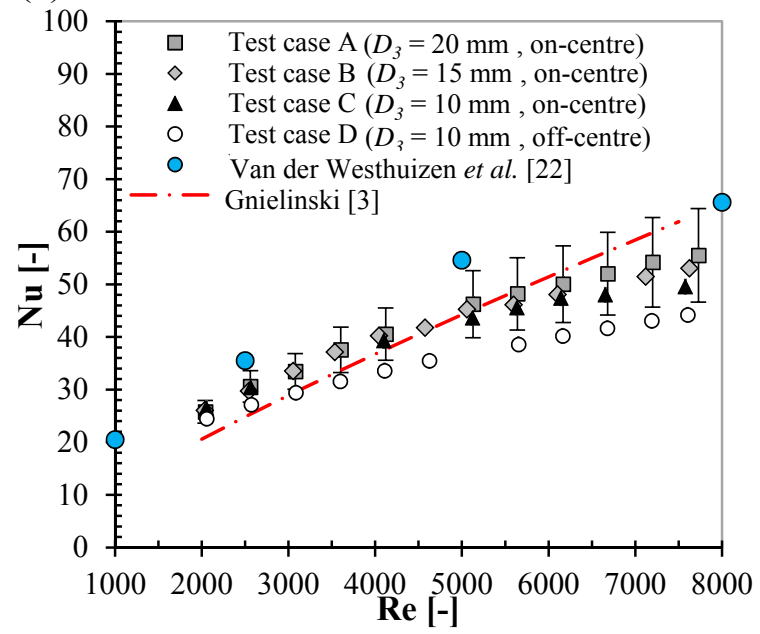

(b)

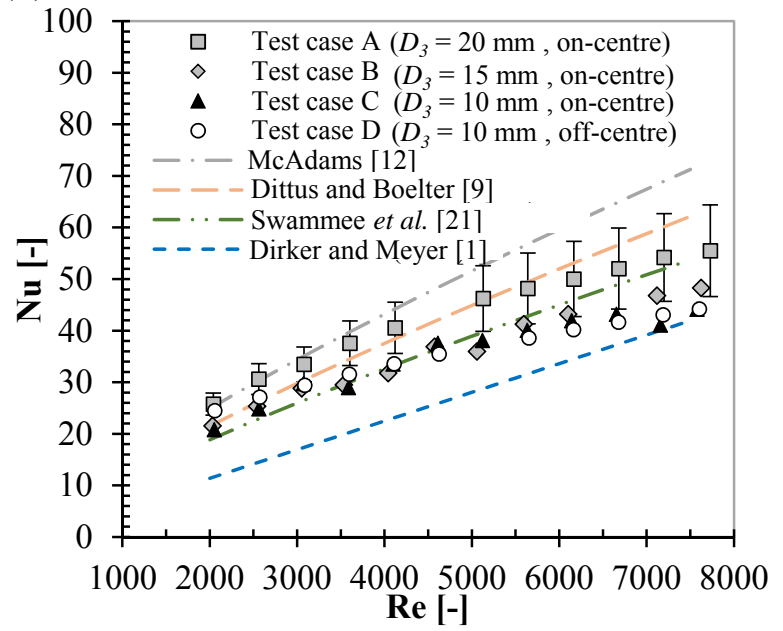

Figure 12: Comparison of experimental results with literature for (a) the entire length using equation (9) and (b) for $x / D_{h}>10$ using equation (10) 


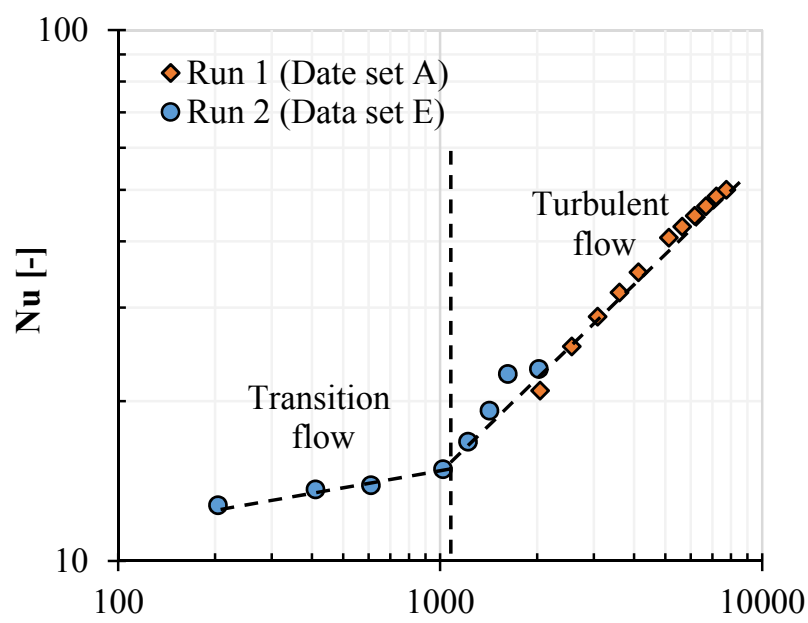

Figure 13: Upper limit of the transitional flow regime 

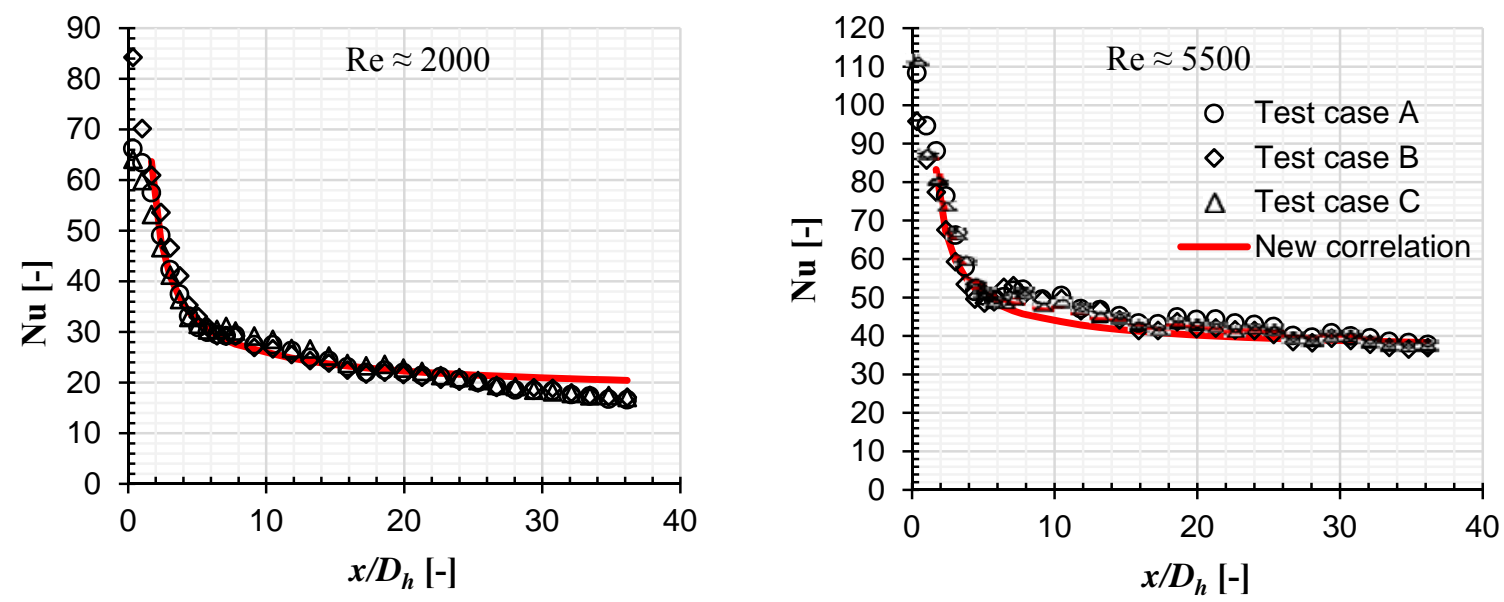

Figure 14: Local Nusselt numbers from experimental results and the developed correlation 


\section{List of tables}

Table 1: Test cases with calculated average Nusselt numbers for $x / D_{h}>10$

Table 2: Condensed uncertainties for test case $\mathrm{A}\left(D_{3}=20 \mathrm{~mm}\right)$ 
Table 1: Test cases with calculated average Nusselt numbers for $x / D_{h}>10$

\begin{tabular}{|c|c|c|c|c|c|c|c|c|c|}
\hline \multirow{2}{*}{\multicolumn{2}{|c|}{$\begin{array}{c}A \\
D_{3}=20 \mathrm{~mm}\end{array}$}} & \multicolumn{2}{|c|}{ B } & \multicolumn{2}{|c|}{$\mathrm{C}$} & \multicolumn{2}{|c|}{ D } & \multicolumn{2}{|c|}{$\mathbf{E}$} \\
\hline & & $D_{3}=$ & $\mathbf{m m}$ & $D_{3}=$ & $\mathbf{m m}$ & $\begin{array}{r}D_{3}= \\
\text { off- }\end{array}$ & $\begin{array}{l}\text { mm } \\
\text { tre }\end{array}$ & $D_{3}=$ & $\mathbf{m m}$ \\
\hline $\mathbf{R e}$ & $\mathbf{N u}$ & $\mathbf{R e}$ & $\mathbf{N u}$ & $\operatorname{Re}$ & $\mathbf{N u}$ & $\mathbf{R e}$ & $\mathbf{N u}$ & $\mathbf{R e}$ & $\mathbf{N u}$ \\
\hline 2041 & 21.0 & 2033 & 21.5 & 2051 & 20.8 & 2055 & 18.8 & 2026 & 23.0 \\
\hline 2561 & 25.4 & 2543 & 25.4 & 2562 & 24.8 & 2570 & 21.1 & 1624 & 22.5 \\
\hline 3079 & 28.9 & 3053 & 28.8 & 3072 & 29.7 & 3085 & 23.0 & 1423 & 19.2 \\
\hline 3604 & 32.1 & 3534 & 29.5 & 3587 & 28.9 & 3596 & 24.9 & 1221 & 16.8 \\
\hline 4122 & 35.0 & 4042 & 31.8 & 4097 & 33.5 & 4109 & 26.8 & 1022 & 14.9 \\
\hline 4649 & 41.4 & 4575 & 36.9 & 4609 & 37.6 & 4624 & 28.6 & 610 & 13.9 \\
\hline 5129 & 40.7 & 5057 & 36.0 & 5121 & 38.1 & 5136 & 34.0 & 410 & 13.6 \\
\hline 5640 & 42.7 & 5594 & 41.3 & 5633 & 40.0 & 5651 & 32.3 & 205 & 12.7 \\
\hline 6167 & 44.7 & 6103 & 43.2 & 6141 & 41.9 & 6161 & 33.8 & & \\
\hline 6681 & 46.6 & 6607 & 49.0 & 6653 & 43.2 & 6676 & 35.5 & & \\
\hline 7200 & 48.6 & 7117 & 46.8 & 7157 & 41.1 & 7188 & 37.1 & & \\
\hline 7728 & 50.1 & 7624 & 48.3 & 7576 & 44.2 & 7602 & 38.2 & & \\
\hline
\end{tabular}


Table 2: Condensed uncertainties for test case $A\left(D_{3}=20 \mathrm{~mm}\right)$

\begin{tabular}{|c|c|c|c|c|c|c|c|c|}
\hline $\mathbf{R e}$ & $\begin{array}{c}\boldsymbol{\delta} \dot{\boldsymbol{q}}_{\text {elec }} \\
(\%)\end{array}$ & $\begin{array}{c}\delta \bar{T}_{\text {bin }} \\
\text { and } \\
\delta \overline{\boldsymbol{T}}_{\text {bout }} \\
\left({ }^{\circ} \mathrm{C}\right)\end{array}$ & $\begin{array}{c}\boldsymbol{\delta} \boldsymbol{T}_{T L C} \\
\left({ }^{\circ} \mathrm{C}\right)\end{array}$ & $\begin{array}{c}\boldsymbol{\delta} \boldsymbol{R}_{\text {adh }} \\
(\%)\end{array}$ & $\begin{array}{c}\boldsymbol{\delta} \Delta T_{a d h} \\
\left({ }^{\circ} C\right)\end{array}$ & $\begin{array}{l}\delta T_{w} \\
\left({ }^{\circ} C\right)\end{array}$ & $\begin{array}{c}\boldsymbol{\delta} \boldsymbol{h}_{\boldsymbol{i}} \text { for } \\
\text { highest } \\
\boldsymbol{h}_{\boldsymbol{i}} \\
(\%)\end{array}$ & $\begin{array}{c}\boldsymbol{\delta} \boldsymbol{h}_{\boldsymbol{a v g}} \\
(\%)\end{array}$ \\
\hline 2041 & \multirow[t]{6}{*}{0.794} & \multirow[t]{6}{*}{0.0389} & \multirow[t]{6}{*}{0.0015} & \multirow[t]{6}{*}{8.81} & \multirow[t]{6}{*}{0.348} & \multirow[t]{6}{*}{0.348} & 17.7 & 9.2 \\
\hline 3079 & & & & & & & 20.4 & 10.0 \\
\hline 4121 & & & & & & & 24.9 & 12.1 \\
\hline 5129 & & & & & & & 28.2 & 13.6 \\
\hline 6167 & & & & & & & 27.7 & 14.4 \\
\hline 7200 & & & & & & & 29.9 & 15.6 \\
\hline
\end{tabular}

